Supporting Information for

\title{
Bioinspired Thiophosphorodichloridate Reagents for Chemoselective
}

\section{Histidine Bioconjugation}

Shang Jia ${ }^{\dagger}$, Dan $\mathrm{He}^{\dagger}$ and Christopher J. Chang $\dagger^{\dagger *}$

$\dagger$ Department of Chemistry, University of California, Berkeley, CA 94720, USA

†Department of Molecular and Cell Biology, University of California, Berkeley, CA 94720, USA

$\S$ Howard Hughes Medical Institute, University of California, Berkeley, CA 94720, USA

\section{Table of Contents}

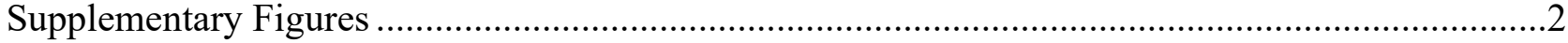

Table S1 Stability of TPAC-labeled Fmoc-His-OH ..........................................................2

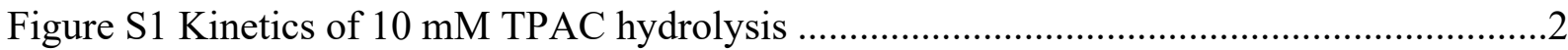

Figure S2 Stability of TPAC-labeled Fmoc-His-OH.........................................................

Figure S3 Reactivity of TPAC toward small molecule histidine and cysteine..........................3

Figure S4 Labeling of model peptides by TPAC ..............................................................

Figure S5 TPAC labeling of ribonuclease A (RNaseA) .....................................................

Figure S6 LC-MS/MS analysis of digested TPAC-labeled RNase A. ......................................6

Figure S7 LC-MS/MS analysis of digested TPAC-labeled calmodulin....................................7

Figure S8 LC-MS/MS analysis of digested TPAC-labeled myoglobin......................................7

Figure S9 LC-MS/MS analysis of digested TPAC-labeled lysozyme.....................................8

Figure S10 Labeling of HeLa lysate with TPAC .................................................................9

Figure S1 1 Structure and molecular weight of model azide compounds ............................... 10

Figure S12 Extracted precursor ion chromatogram .......................................................10

Figure S13 Functionalization of His-tag on mCherry to enable protein delivery ....................11

Figure S14 Western blot and coomassie stain of GFP and mCherry. ..................................12

Figure S15 Z-stack imaging of protein delivery into HeLa cells. .........................................12

Procedures and Characterization Methods ............................................................................ 13

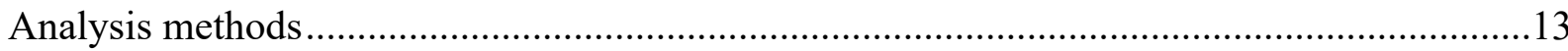

Enzymatic digestion of TPAC-labeled protein for LC-MS/MS analysis ..............................13

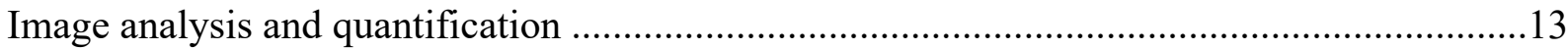

Expression and purification of ribonuclease A (RNaseA) ...............................................14

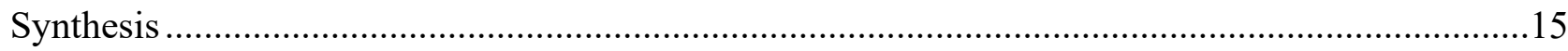

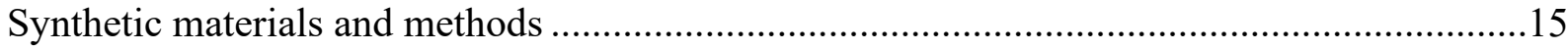

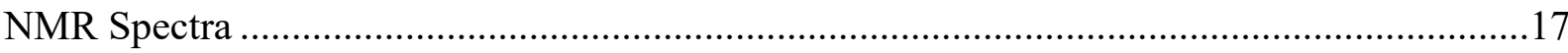

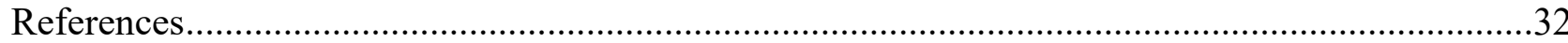




\section{Supplementary Figures}

Table S1 Stability of TPAC-labeled Fmoc-His-OH Purified TPAC-labeled Fmoc-His-OH (0.5 mM, 200x in DMSO) was treated under the following conditions in water (1-7) or PBS (8-12) and analyzed by HPLC after indicated period of time.

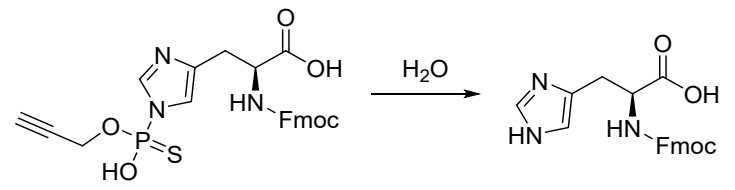

$\begin{array}{ccccc}\text { Entry } & \text { Additive (concentration) } & \text { Temperature } /{ }^{\circ} \mathrm{C} & \text { Time } / \mathrm{h} & \text { Hydrolysis percentage } \\ 1 & \text { Formic acid }(1 \mathrm{M}) & 25 & 1 & 1 \% \\ 2 & \text { Formic acid }(1 \mathrm{M}) & 25 & 14 & 15 \% \\ 3 & \mathrm{HCl}(0.2 \mathrm{M}) & 25 & 1 & <1 \% \\ 4 & \mathrm{HCl}(0.2 \mathrm{M}) & 25 & 14 & 20 \% \\ 5 & \mathrm{NH}_{3} \cdot \mathrm{H}_{2} \mathrm{O}(1 \mathrm{M}) & 25 & 1 & <1 \% \\ 6 & \mathrm{NH}_{3} \cdot \mathrm{H}_{2} \mathrm{O}(1 \mathrm{M}) & 25 & 14 & <1 \% \\ 7 & \mathrm{NaOH}(0.2 \mathrm{M}) & 25 & 1 & \text { n.d. } \\ 8 & \mathrm{PBS} & 80 & 1 & 2 \% \\ 9 & \mathrm{PBS} & 80 & 14 & 32 \% \\ 10 & \mathrm{TCEP}(5 \mathrm{mM})^{b} & 65 & 0.5 & <1 \% \\ 11 & \text { Dithiothreitol }(5 \mathrm{mM}) & 65 & 0.5 & 1 \% \\ 12 & \text { Iodoacetamide }(10 \mathrm{mM}) & 37 & 1 & 2 \% \\ { }^{a} \text { Fmoc protection group was cleaved during treatment. } & { }^{b} \text { Tris }(2 \text {-carboxyethyl)phosphine. }\end{array}$

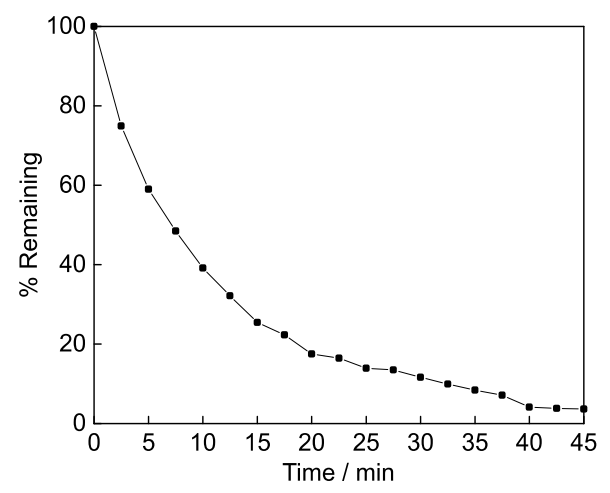

Figure S1 Kinetics of $10 \mathrm{mM}$ TPAC hydrolysis in phosphate buffered $1: 1 \mathrm{D}_{2} \mathrm{O} / \mathrm{CD}_{3} \mathrm{CN}(100 \mathrm{mM}$ $\mathrm{K}_{3} \mathrm{PO}_{4}$, adjusted to $\mathrm{pD} 7.0$ by $\mathrm{pH}$ strip), monitored by ${ }^{1} \mathrm{H}$ NMR. The observed $\mathrm{t}_{1 / 2}$ is $9.2 \mathrm{~min}$. 

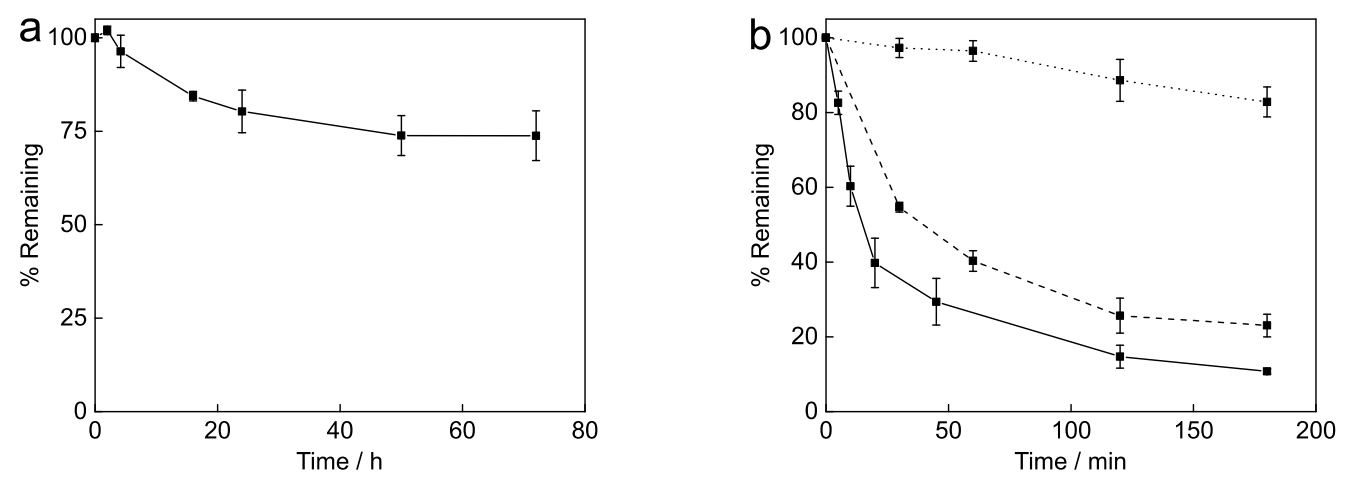

Figure S2 Stability of TPAC-labeled Fmoc-His-OH in (a) fetal bovine serum and (b) HeLa cell lysate (1 $\mathrm{mg} / \mathrm{mL}$ protein in $50 \mathrm{mM}$ HEPES buffer, $\mathrm{pH} 7.5$ ). Solid line: $37^{\circ} \mathrm{C}$, dashed line: $25^{\circ} \mathrm{C}$, dotted line: $4^{\circ} \mathrm{C}$. Purified TPAC-labeled Fmoc-His-OH (0.1 mM, 100x in DMSO) was diluted and treated under each condition, protein precipitated by methanol and then analyzed by HPLC $(n=3$, average \pm s.d.).
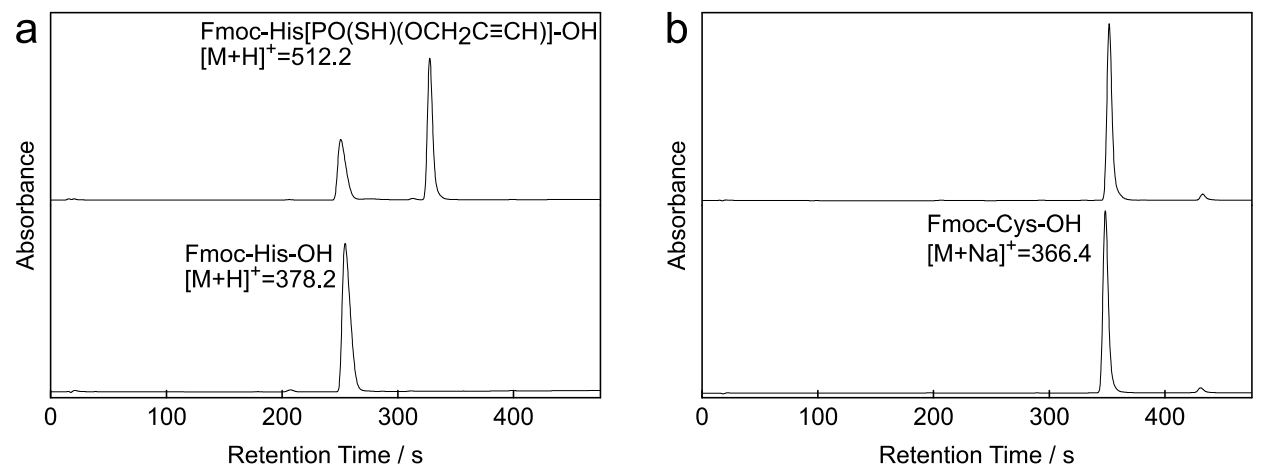

Figure S3 Reactivity of TPAC toward small molecule histidine and cysteine. (a) HPLC chromatograms showing the reactivity of TPAC toward Fmoc-His-OH. Top: reaction mixture of TPAC and Fmoc-His-OH. Bottom: Fmoc-His-OH. (b) HPLC chromatograms showing TPAC is not reactive toward Fmoc-Cys-OH. Top: reaction mixture of TPAC and Fmoc-Cys-OH. Bottom: Fmoc-Cys-OH. 

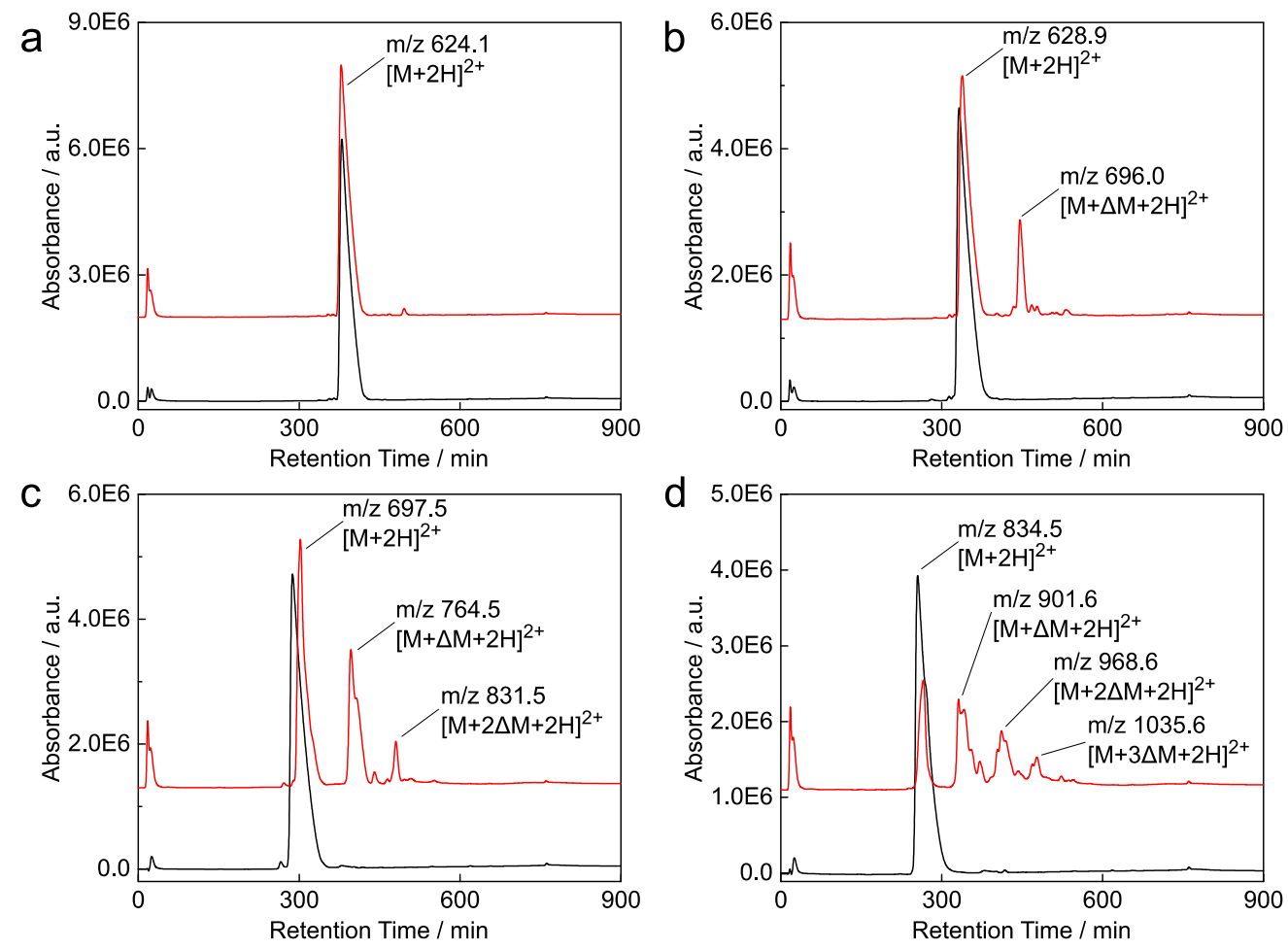

Figure S4 Labeling of model peptides by TPAC. Aqueous solution buffered by $50 \mathrm{mM} \mathrm{HEPES}$ at $\mathrm{pH}$ 8.5 containing $0.3 \mathrm{mM}$ (a) Fmoc-GRTQEKYSG, (b) Fmoc-GRTHEKYSG, (c) Fmoc-GRTHHEKYSG (d) Fmoc-GRTHHHHEKYSG was treated $5 \mathrm{mM}$ TPAC for $1 \mathrm{~h}$ and subject to LC-MS analysis. Black lines represent starting peptide solution; red lines represent reaction mixture. $\Delta \mathrm{M}=133.96$, corresponding to the mass increase of one TPAC modification. 

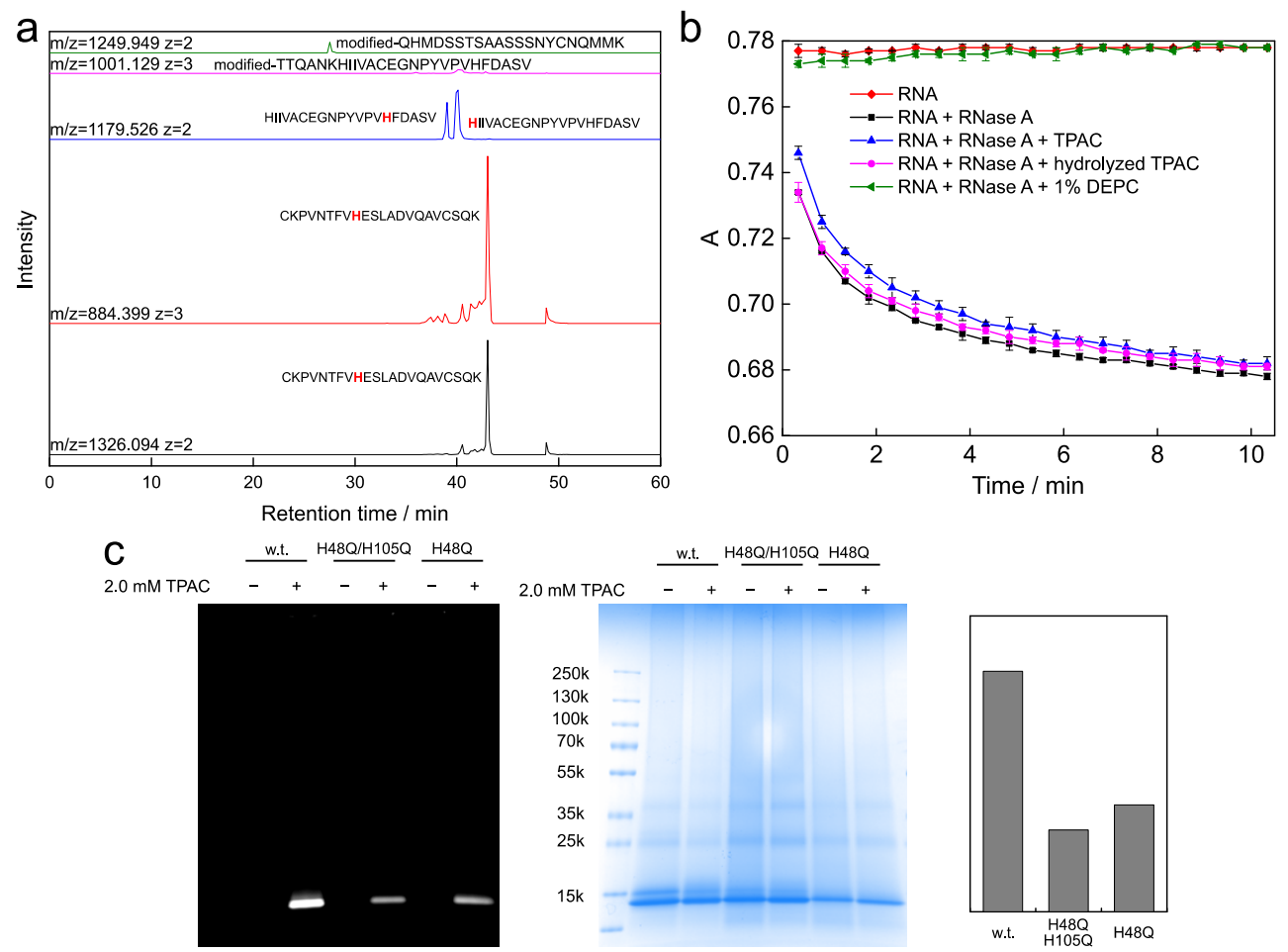

Figure S5 TPAC labeling of ribonuclease A (RNaseA) (a) LC-MS analysis of digested TPAC-labeled RNaseA showing extracted precursor ion chromatograms of peptides carrying TPAC modification $(\triangle \mathrm{M}=133.959)$. Identified modification sites by MS2 spectra are highlighted in red. (b) Activity assay shows TPAC does not react much with active site histidine residues on RNase A. RNase A $(0.5 \mathrm{mg} / \mathrm{mL})$ was treated with $2 \mathrm{mM}$ TPAC, $2 \mathrm{mM}$ hydrolyzed TPAC or 1\% diethylpyrocarbonate (DEPC) before incubating with RNA in $25 \mathrm{mM}$ HEPES buffered at $\mathrm{pH}$ 8.5. The absorbance of RNA is monitored at 300 $\mathrm{nm}(\mathrm{n}=3$, average \pm s.d.). (c) Confirmation of TPAC modification site on RNaseA by site-directed mutagenesis. Wildtype RNaseA, RNaseA H48Q/H105Q and RNaseA H48Q were treated with TPAC, conjugated with $\mathrm{Cy} 3-\mathrm{N}_{3}$ by $\mathrm{CuAAC}$ and subject to SDS-PAGE. Left: fluorescence. Middle: coomassie. Right: quantification of TPAC-labeled gel lanes (fluorescence intensity divided by coomassie intensity). 

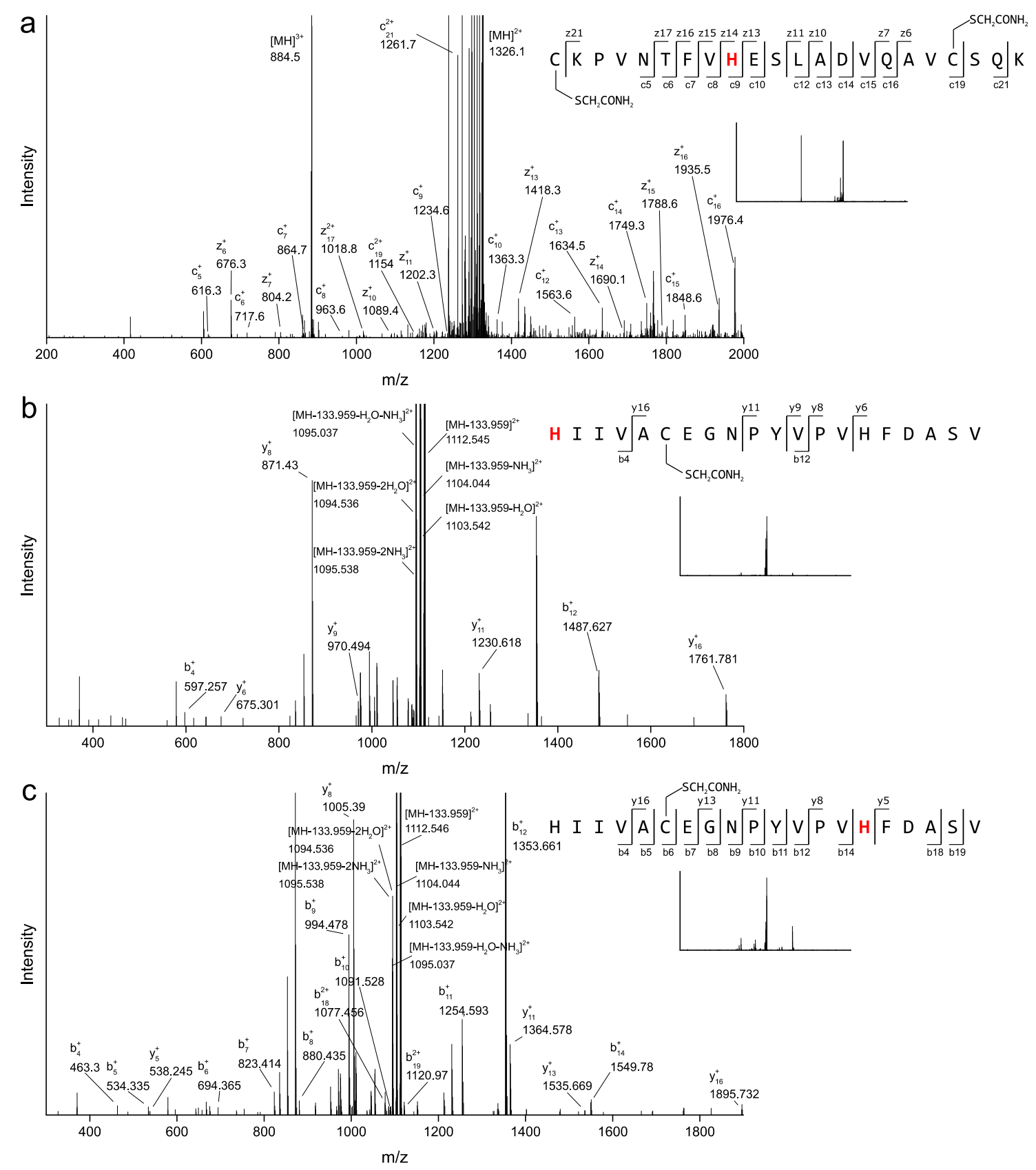

Figure S6 LC-MS/MS analysis of digested TPAC-labeled RNase A. (a) ETD MS/MS spectra and (b),(c) CID MS/MS spectrum of major TPAC-modified peptides from Figure S5a. Y-axis is zoomed in to show fragment peaks; full spectrum is shown as inset. 
a

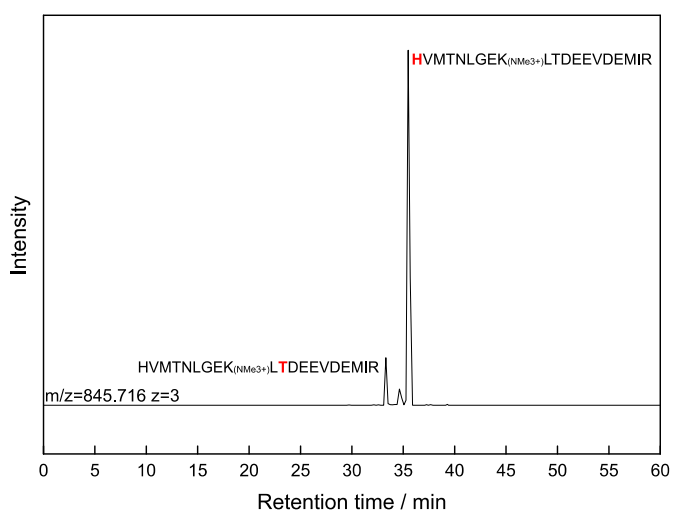

b

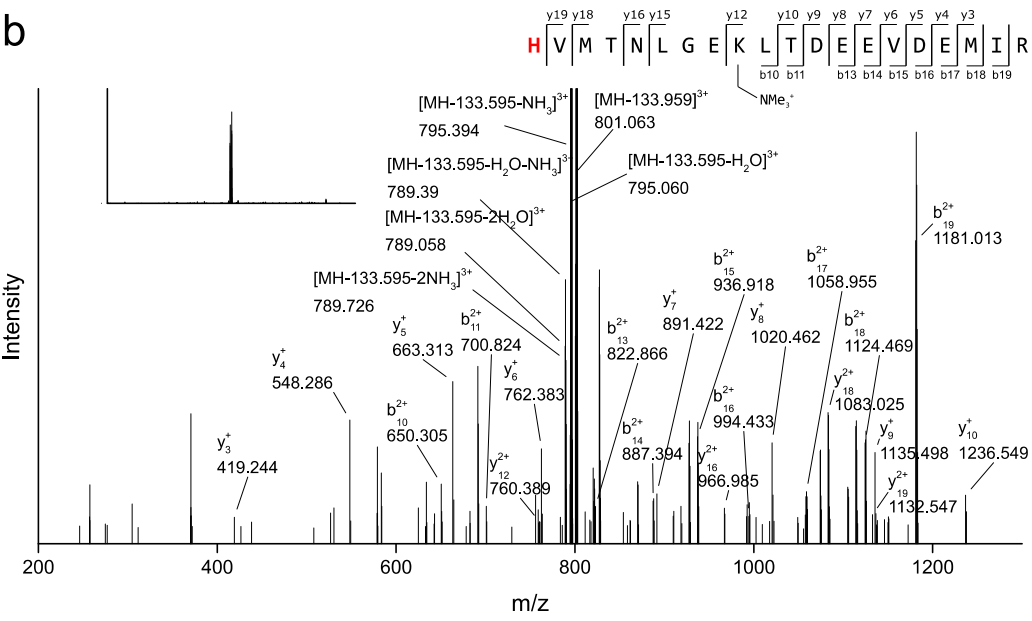

Figure S7 LC-MS/MS analysis of digested TPAC-labeled calmodulin. (a) Extracted precursor ion chromatogram of peptides carrying TPAC modification $(\triangle \mathrm{M}=133.959)$. Identified modification sites by MS2 spectra are highlighted in red. (b) CID MS/MS spectrum of major TPAC-modified peptide. Y-axis is zoomed in to show fragment peaks; full spectrum is shown as inset.
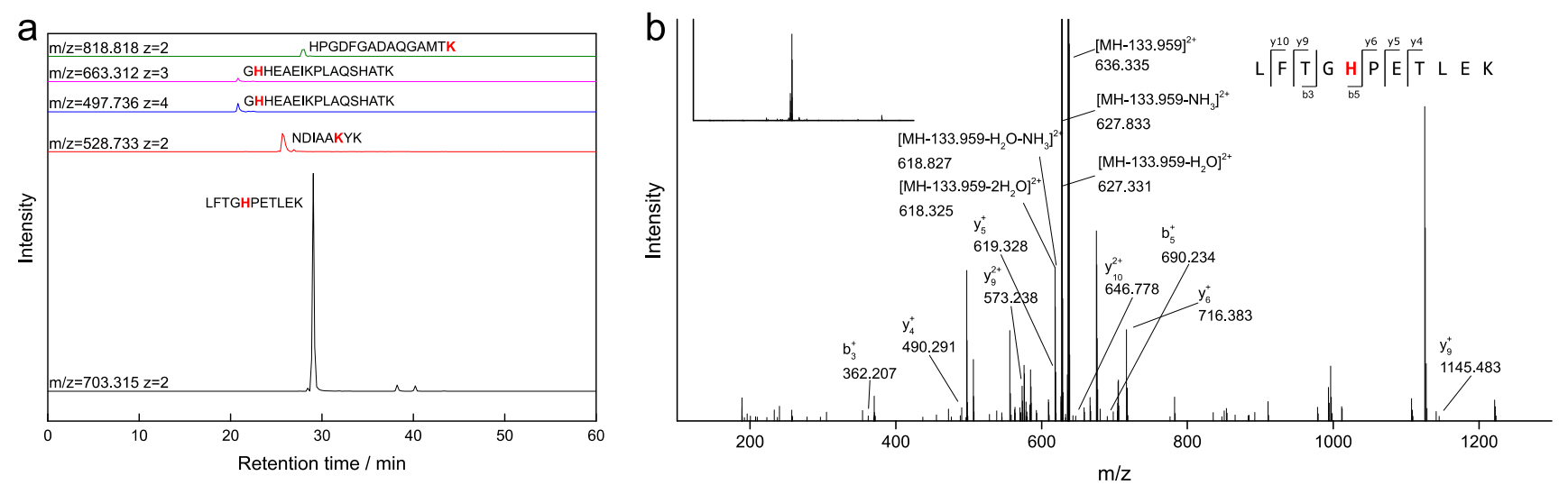

Figure S8 LC-MS/MS analysis of digested TPAC-labeled myoglobin. (a) Extracted precursor ion chromatogram of peptides carrying TPAC modification $(\triangle \mathrm{M}=133.959)$. Identified modification sites by MS2 spectra are highlighted in red. (b) CID MS/MS spectrum of major TPAC-modified peptide. Y-axis is zoomed in to show fragment peaks; full spectrum is shown as inset. 

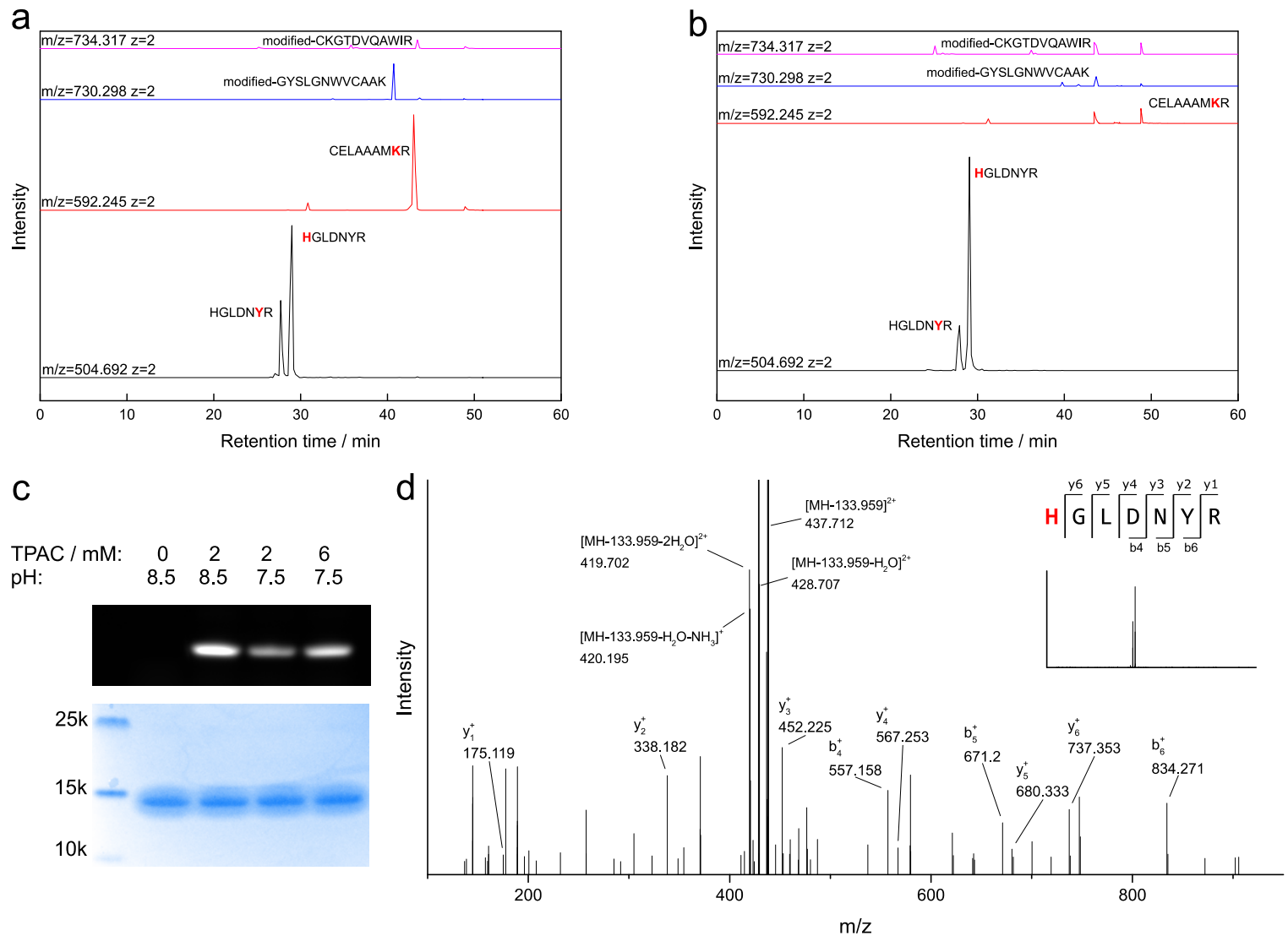

Figure S9 LC-MS/MS analysis of digested TPAC-labeled lysozyme. (a) Extracted precursor ion chromatogram of peptides carrying TPAC modification $(\triangle \mathrm{M}=133.959)$, digested from lysozyme treated with $2 \mathrm{mM}$ TPAC at $\mathrm{pH}$ 8.5. (b) Extracted precursor ion chromatogram of peptides carrying TPAC modification $(\triangle \mathrm{M}=133.959)$, digested from lysozyme treated with $6 \mathrm{mM} \mathrm{TPAC}$ at $\mathrm{pH} 7.5$. Modification sites identified by MS2 spectra are highlighted in red. (c) In-gel fluorescence shows comparable labeling efficiency between these two conditions. Lysozyme was labeled with TPAC, conjugated with $\mathrm{Cy} 3-\mathrm{N}_{3}$ by CuAAC and subject to SDS-PAGE. Top: fluorescence. Bottom: coomassie. (d) CID MS/MS spectrum of major TPAC-modified peptide. Y-axis is zoomed in to show fragment peaks; full spectrum is shown as inset. 

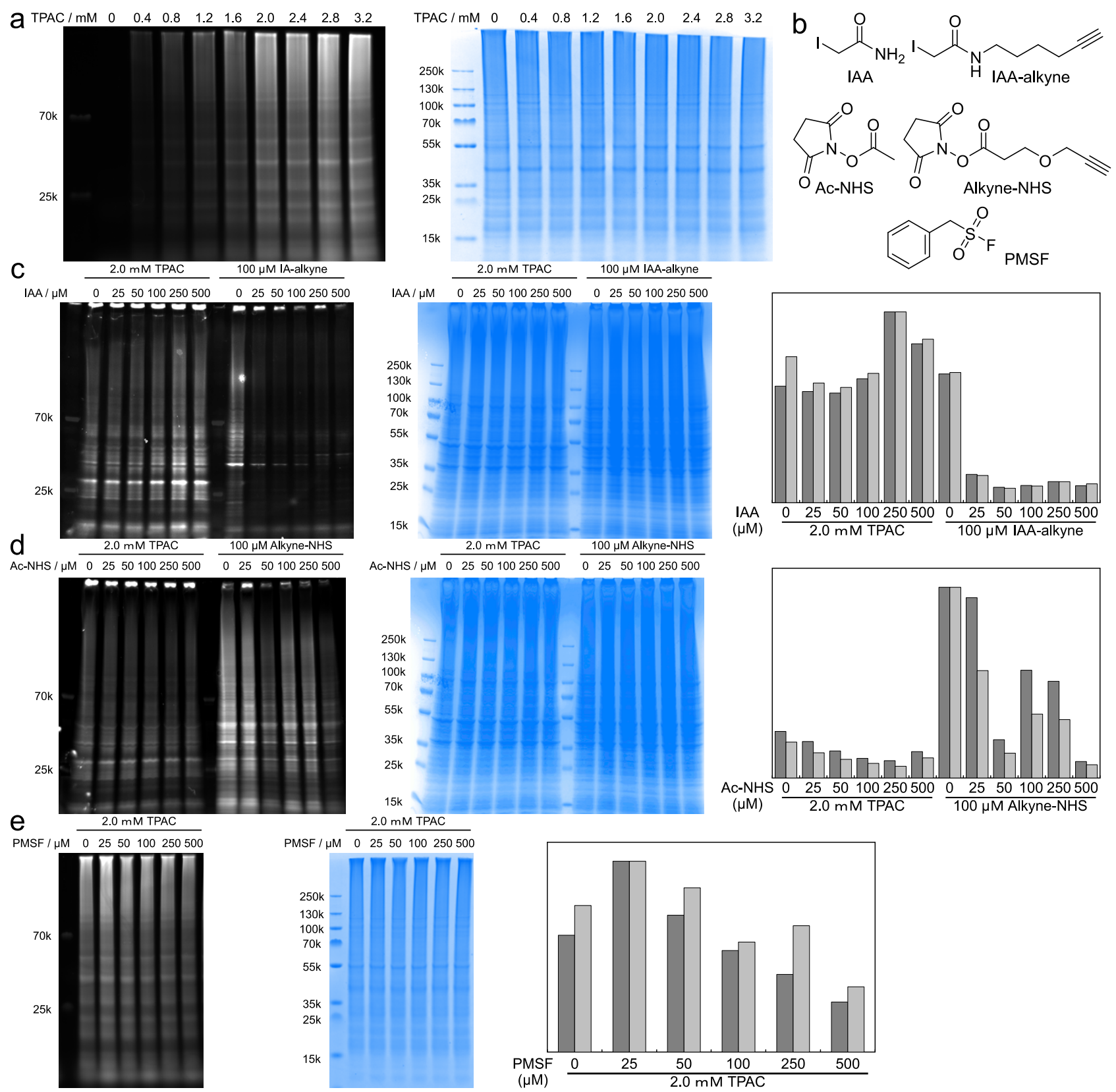

Figure S10 Labeling of HeLa lysate with TPAC in $50 \mathrm{mM}$ HEPES buffer, pH 7.5. (a) Dose-dependent labeling of HeLa proteome with TPAC. Lysates were treated with indicated concentration of TPAC, conjugated with $\mathrm{Cy} 3-\mathrm{N}_{3}$ by CuAAC and analyzed by SDS-PAGE. Left: fluorescence. Right: coomassie. (b) Structures of competing electrophiles: IAA that reacts with cysteine, Ac-NHS that reacts with lysine, and PMSF that reacts with reactive serine. The alkyne-containing IAA-alkyne and alkyne-NHS are used to confirm the blockage of amino acid residues from IAA and Ac-NHS treatment, respectively. HeLa lysates were pretreated for $1 \mathrm{~h}$ with (c) IAA, (d) Ac-NHS or (e) PMSF prior to labeling with alkyne-containing electrophiles; resulting lysates were conjugated with $\mathrm{Cy} 3$-azide by $\mathrm{CuAAC}$ and analyzed by SDS-PAGE. Left: fluorescence. Middle: coomassie. Right: quantification of gel lanes (dark grey: fluorescence intensity, light grey: fluorescence intensity divided by coomassie intensity). 

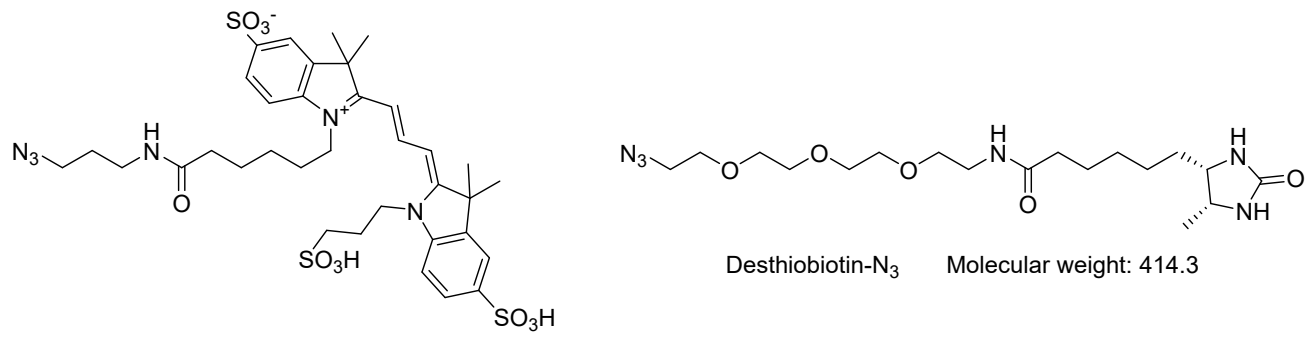

Cy3- $\mathrm{N}_{3} \quad$ Molecular weight: 806.2

Figure S11 Structure and molecular weight of model azide compounds: Cy3- $\mathrm{N}_{3}$ and desthiobiotin- $\mathrm{N}_{3}$.

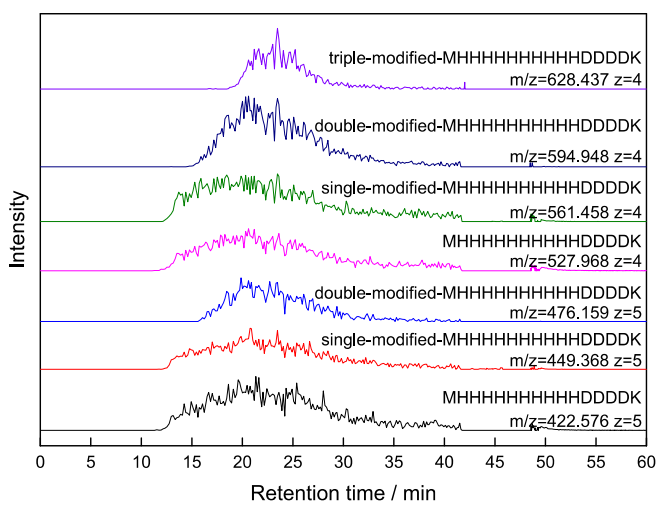

Figure S12 Extracted precursor ion chromatogram of His-tag peptide and major peptides carrying TPAC modification ( $\triangle \mathrm{M}=133.959)$, digested from His-tagged GFP treated with $2 \mathrm{mM}$ TPAC at $\mathrm{pH}$ 8.5. For simplicity, peptides with N-terminal methionine excised and peptides with oxidized methionine are not shown. 

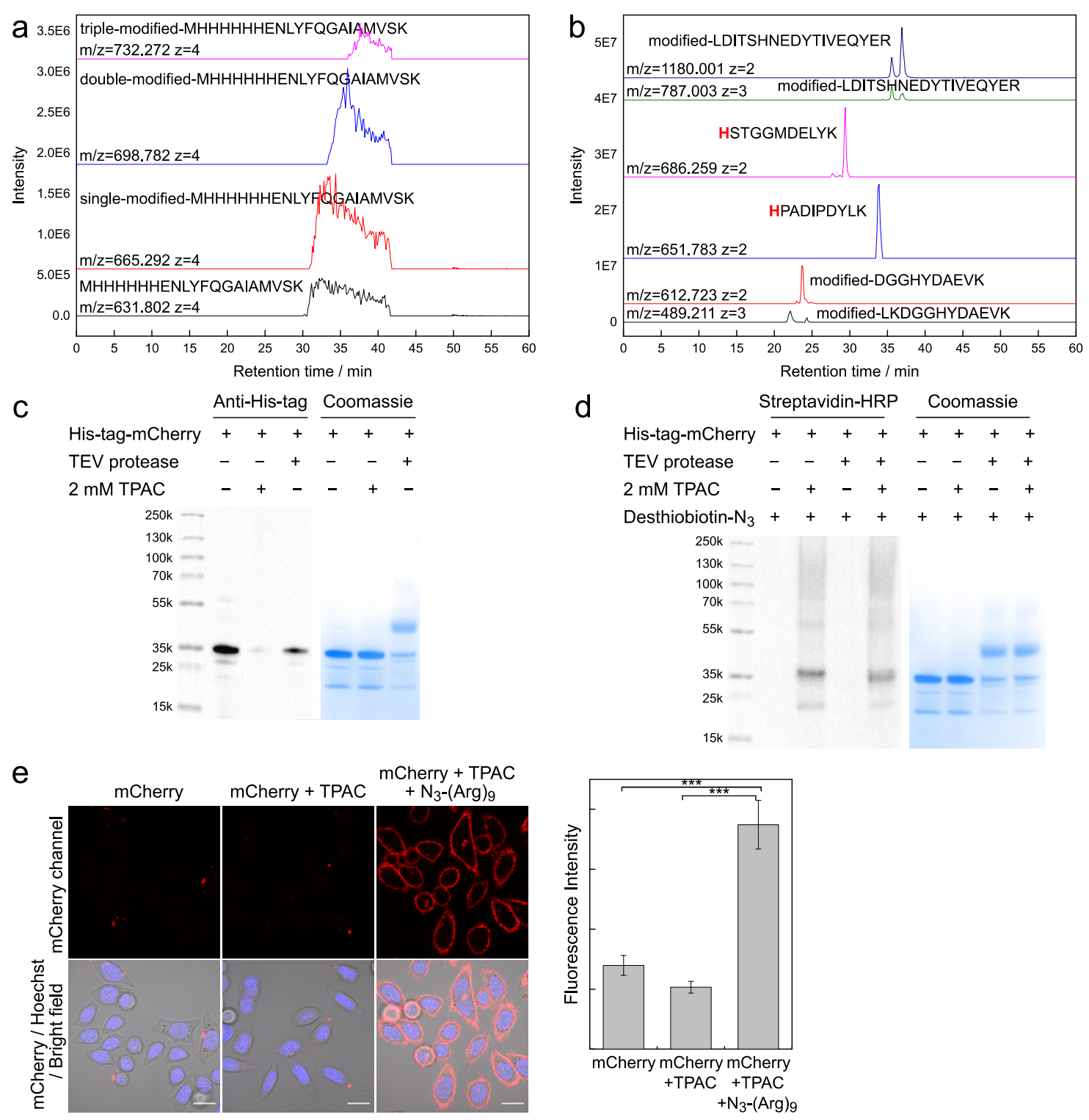

Figure S13 Functionalization of His-tag on mCherry to enable protein delivery. (a) Extracted precursor ion chromatogram of unmodified and TPAC-modified $(\triangle \mathrm{M}=133.959)$ His-tag peptides, digested from His-tagged GFP treated with 2mM TPAC at $\mathrm{pH}$ 8.5. (b) Extracted precursor ion chromatogram of other major TPAC-modified peptides. (c) Western blot and coomassie stain showing that labeling of TPAC with His-tagged mCherry significantly reduces its detection by His-tag antibody. TEV protease was used to cleave off His-tag on this protein for comparison. Cleavage of His-tag leads to less coomassie staining but with similar migration on SDS-PAGE (Figure S14b). (d) Streptavidin-HRP blot and coomassie stain showing that removal of the His-tag reduces the labeling by TPAC. His-tagged mCherry and native mCherry prepared by TEV protease cleavage of His-tag were treated with TPAC, followed by CuAAC with desthiobiotin- $\mathrm{N}_{3}$ and gel-analysis. (e) Transduction of functionilized mCherry into live HeLa cells. Cells were incubated with mCherry $(0.1 \mu \mathrm{g} / \mu \mathrm{L})$, stained with Hoechst 33342 and imaged; quantification is shown on the right ( $\mathrm{n}=3$, average \pm s.d. ${ }^{* *} P \leq 0.001$; two-tailed Student's t-test.) Scale-bars: $20 \mu \mathrm{m}$. 


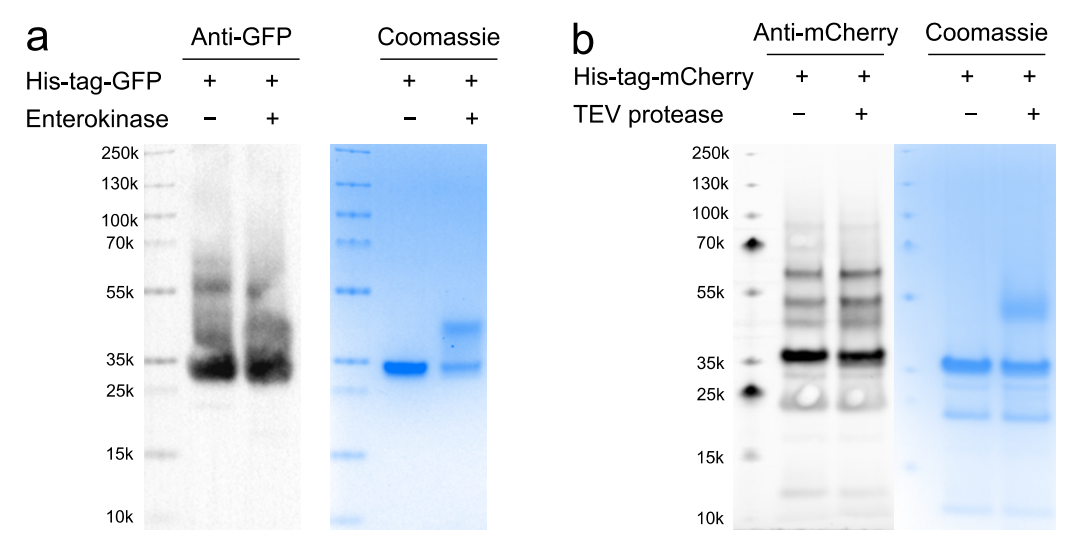

Figure S14 Western blot and coomassie stain of GFP and mCherry. (a) His-tagged GFP and GFP. (b) His-tagged mCherry and mCherry.
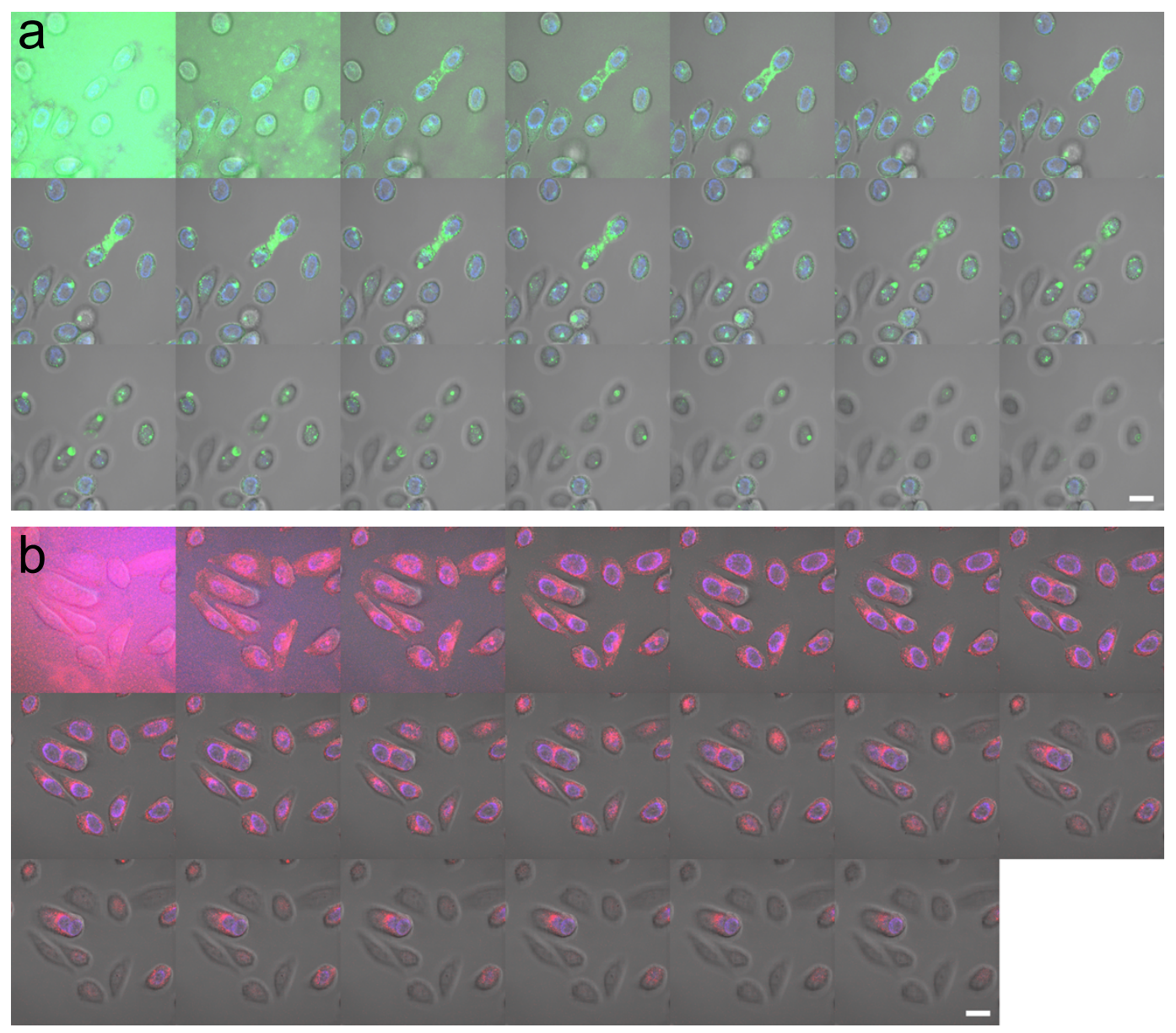

Figure S15 Z-stack imaging of protein delivery into HeLa cells. HeLa cells were treated with TPAC/ $\mathrm{N}_{3}-(\mathrm{Arg})_{9}$ modified (a) His-tagged GFP or (b) His-tagged mCherry and stained with Hoechst 33342. Scale-bars: $20 \mu \mathrm{m}$. 


\section{Procedures and Characterization Methods}

\section{Analysis methods}

Reactions on protected amino acid were analyzed by LC/MS using 1220 Infinity LC (Agilent, Santa Clara CA) coupled with Expression-L Compact Mass Spectrometer (Advion, Ithaca NY). Reaction mixtures with single protected amino acid were separated on a Zorbax rapid resolution cartridge (Agilent). Mixtures with multiple protected amino acids were separated on a Zorbax SB-phenyl column (Agilent, $4.6 \times 250 \mathrm{~mm}, 5 \mu \mathrm{m}$ ). Solvent A was water $+0.05 \%$ formic acid and solvent B was methanol + $0.05 \%$ formic acid. The linear gradient employed for single protected amino acid was $25-100 \% \mathrm{~B}$ in 6.5 min and $100 \%$ B for 1.5 min; for multiple amino acids mixture was $45-100 \%$ B in 30 min and $100 \%$ B for $10 \mathrm{~min}$.

Intact protein samples were analyzed using a Synapt G2-Si mass spectrometer equipped with an ionKey ESI source (Protein ionKey, C4, $1.7 \mu \mathrm{m}, 0.150 \times 50 \mathrm{~mm}, 300 \AA$ ), operated in the positive ion mode, and connected in line with an Acquity M-class LC system (Waters, Milford MA). This instrumentation is located in the QB3/Chemistry Mass Spectrometry Facility at the University of California, Berkeley. The obtained mass spectra were deconvoluted using UniDec. ${ }^{1}$

Proteolytically digested protein samples were analyzed using an LTQ-Orbitrap-XL mass spectrometer equipped with an electrospray ionization (ESI) source, operated in the positive ion mode, and connected in line with an UltiMate3000 RSLCnano liquid chromatography (LC) system (Thermo Fisher). The LC system was equipped with a reversed-phase analytical column (Acclaim PepMap100, C18, $3 \mu \mathrm{m}, 0.075$ $\times 250 \mathrm{~mm}, 100 \AA$, Thermo Fisher). The obtained data were processed with Trans-Proteomic Pipeline using the Comet search algorithm (Institute for Systems Biology, Seattle WA). ${ }^{2}$ The MS2 spectra were annotated with a mass tolerance of $15 \mathrm{ppm}$. The extracted-ion chromatograms (XIC) of MS1 were generated from the .ms1 file from RawConverter, using an in-house script that picks correctly-charged precursor ions with a mass tolerance of $20 \mathrm{ppm}$.

\section{Enzymatic digestion of TPAC-labeled protein for LC-MS/MS analysis}

Protein $(0.5 \mathrm{mg} / \mathrm{mL})$ was labeled with $2 \mathrm{mM}$ TPAC following the general procedure unless otherwise noted. Labeled protein was precipitated by acetone to remove excess TPAC. The pellet was dissolved in $25 \mathrm{mM}$ HEPES, pH 8.0 containing $6 \mathrm{M}$ urea and subject to reduction (TCEP, $5 \mathrm{mM}, 20 \mathrm{~min}$ ) and alkylation (iodoacetamide, $10 \mathrm{mM}, 40 \mathrm{~min}$ at $37^{\circ} \mathrm{C}$ ). Protein was precipitated again by acetone, suspended in $25 \mathrm{mM}$ HEPES, pH 8.0 and digested by trypsin (1:20, Promega, Madison WI) overnight at $37^{\circ} \mathrm{C}$.

\section{Image analysis and quantification}

ImageJ (National Institutes of Health) was used for image analysis. For quantification of fluorescence intensity, each image was set to 8-bit greyscale and inverted. The fluorescence intensity was estimated 
using non-calibrated OD function. The area of cells were selected based on the brightfield image using edge detection and morphological operations. ${ }^{3}$ The statistics of selected pixels was then measured by the "Measure" function and the average fluorescence intensity was obtained by dividing the integrated density (IntDen) over area. For each biological replicate, five images of different fields of cells were analyzed using this process and the values were combined for statistical analysis.

\section{Expression and purification of ribonuclease A (RNaseA)}

Synthetic genes for wildtype bovine pancreatic RNaseA excluding the signal peptide, and its mutant, H48Q, H48Q/H105Q, were ordered from Quintarabio (Hayward CA). The genes were cloned into pNIC28-Bsa4 containing N-terminal 6xHis-TEV cassette by Gibson assembly and confirmed by sequencing.

E. coli cell line Rosetta2 (DE3) pLysS harboring RNaseA-expressing plasmid were grown in 1 L LB medium containing kanamycin $(50 \mu \mathrm{g} / \mathrm{L})$ at $37^{\circ} \mathrm{C}$ until $\mathrm{OD} 600$ reached 0.8 . At this time, protein expression was induced by addition of $1 \mathrm{mM}$ IPTG. After induction, the cells were shaken at $37{ }^{\circ} \mathrm{C}$ for $4.5 \mathrm{~h}$ and then centrifuged. The cell paste was suspended in $35 \mathrm{~mL}$ of $20 \mathrm{mM}$ Tris- $\mathrm{HCl}, \mathrm{pH} 8.0$ and subject to sonication on ice. The lysate was centrifuged at $4^{\circ} \mathrm{C}$ to discard the soluble protein. The pellet containing inclusion bodies were washed by suspending in $35 \mathrm{~mL}$ of $20 \mathrm{mM}$ Tris- $\mathrm{HCl} \mathrm{pH} 8.0$ buffer containing $2 \mathrm{M}$ urea, $0.5 \mathrm{M} \mathrm{NaCl}$ and $0.5 \%$ Triton $\mathrm{X}-100$. The suspension was centrifuged again; the pellet was dissolved by mixing with $35 \mathrm{~mL}$ of $20 \mathrm{mM}$ Tris- $\mathrm{HCl} \mathrm{pH} 8.0$ buffer containing $6 \mathrm{M}$ guanidine $\mathrm{HCl}, 5 \mathrm{mM}$ 2-mercaptoethanol, $0.5 \mathrm{M} \mathrm{NaCl}$ and $5 \mathrm{mM}$ imidazole for $45 \mathrm{~min}$ at room temperature. The resulting solution was passed through a filter and loaded onto a $5 \mathrm{~mL}$ HisTrap FF column (GE Healthcare). The column was washed with $50 \mathrm{~mL}$ of $20 \mathrm{mM}$ Tris- $\mathrm{HCl} \mathrm{pH} 8.0$ buffer containing $6 \mathrm{M}$ guanidine $\mathrm{HCl}, 1 \mathrm{mM}$ 2-mercaptoethanol, $0.5 \mathrm{M} \mathrm{NaCl}$ and $5 \mathrm{mM}$ imidazole, followed by washing with $50 \mathrm{~mL}$ of Tris- $\mathrm{HCl} \mathrm{pH} 8.0$ buffer containing $6 \mathrm{M}$ urea, $0.5 \mathrm{M} \mathrm{NaCl}, 20 \mathrm{mM}$ imidazole, $2 \mathrm{mM} \mathrm{GSH}$ and $0.5 \mathrm{mM}$ GSSG. Protein refolding was performed using a linear gradient wash, starting from the previous washing buffer containing $6 \mathrm{M}$ urea to final washing buffer without urea $(150 \mathrm{~mL}, 75 \mathrm{~min})$. The column was further washed with $50 \mathrm{~mL}$ buffer without urea, and the protein was eluted using a linear gradient starting with $20 \mathrm{mM}$ Tris- $\mathrm{HCl} \mathrm{pH} 8.0$ buffer containing $5 \mathrm{mM}$ imidazole, $0.5 \mathrm{M} \mathrm{NaCl}$ and ending with

the same buffer containing $500 \mathrm{mM}$ imidazole. Fractions containing RNaseA were combined, concentrated by ultrafiltration and frozen in aliquots for later processing.

For cleavage of the 6xHis-tag linked by TEV-tag on RNaseA, protein solution was buffer-exchanged into $50 \mathrm{mM}$ HEPES $\mathrm{pH} 8.5$ by ultrafiltration. The cleavage was initiated by adding $1.5 \mathrm{mM}$ DTT and 0.05 equivalent of TEV preotease and incubated at $25^{\circ} \mathrm{C}$ for $12 \mathrm{~h}$. The remaining DTT was removed by ultrafiltration and the obtained protein was used for TPAC labeling analysis. 


\section{Synthesis}

\section{Synthetic materials and methods}

Unless otherwise noted, all commercial reagents were used without further purification. All reactions utilizing air- or moisture-sensitive reagents were performed in dried glassware under an atmosphere of dry $\mathrm{N}_{2}$. THF used for anhydrous reactions was dried and stored over $4 \AA$ molecular sieves. 2-Azidoethanol ${ }^{4}$ and succinimidyl 3-azidopropanoate 5 were synthesized according to literature procedure. 3-Azidopropanoic acid was purchased from Click Chemistry Tools. H-(Arg) $)_{9}-\mathrm{OH}$ trifluoroacetate salt was purchased from Bachem (Bubendorf, Switzerland). All other reagents were purchased from Sigma-Aldrich. ${ }^{1} \mathrm{H} \mathrm{NMR},{ }^{13} \mathrm{C} \mathrm{NMR}$ and ${ }^{31} \mathrm{P} \mathrm{NMR}$ spectra were collected in $\mathrm{CDCl}_{3}$, $\mathrm{MeOD}$ or acetone (Cambridge Isotope Laboratories, Cambridge MA) at $25{ }^{\circ} \mathrm{C}$ on AVB-400, AVQ-400 or AV-600 spectrometers at the College of Chemistry NMR Facility at the University of California, Berkeley. All chemical shifts in ${ }^{1} \mathrm{H}$ NMR and ${ }^{13} \mathrm{C}$ NMR are reported in the standard $\delta$ notation of ppm relative to residual solvent peak $\left(\mathrm{CDCl}_{3} \delta \mathrm{H}=7.26, \delta \mathrm{C}=77.16 ; \mathrm{MeOD} \delta \mathrm{H}=3.31, \delta \mathrm{C}=49.00\right.$; acetone: $\delta \mathrm{H}=2.05, \delta \mathrm{C}=29.84)$, and for ${ }^{31} \mathrm{P}$ NMR $85 \%$ phosphoric acid in sealed capillary tube is used as internal standard $(\delta \mathrm{P}=0.00)$. Splitting patterns are indicated as follows: s, singlet; $d$, doublet; $\mathrm{t}$, triplet; $\mathrm{q}$, quartet; $\mathrm{m}$, multiplet; br, broad. Low resolution election ionization mass spectral analysis was carried out using Agilent 5975C 7890A GC/MS System. High resolution mass spectral analysis (ESI-MS and APCI-MS) were carried out at LBNL Catalysis Facility at the Lawrence Berkeley National Laboratory (Berkeley Lab) using PerkinElmer AxION® 2 TOF MS.

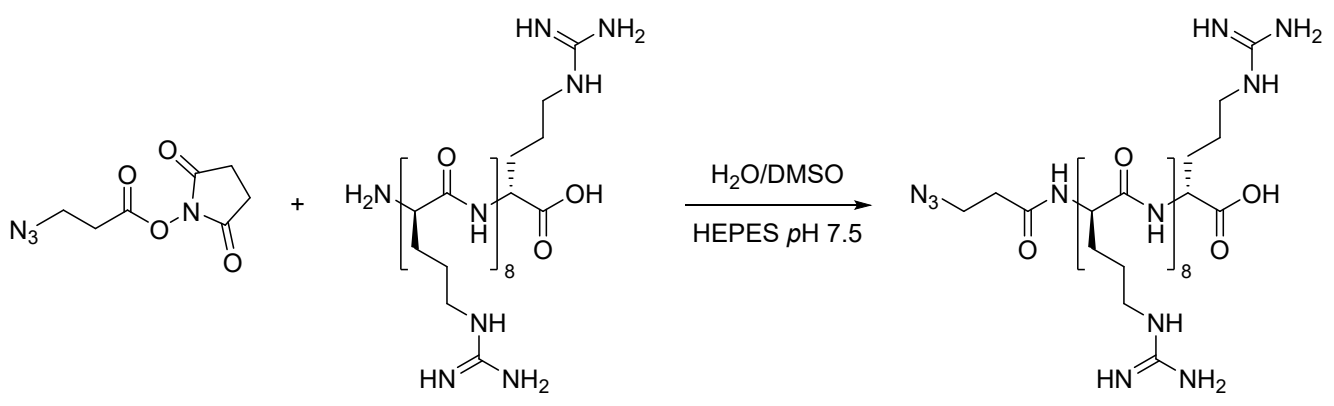

3-Azidoacetyl-(Arg) ${ }_{9}-\mathbf{O H}$. H-(Arg) ${ }_{9}-\mathrm{OH}$ trifluoroacetate salt (1 mg, approx. $\left.0.5 \mu \mathrm{mol}\right)$ was dissolved in $400 \mu \mathrm{L} \mathrm{H}_{2} \mathrm{O}$ in an Eppendorf tube. To this solution was added HEPES buffer $(100 \mu \mathrm{L}, 50 \mathrm{mM} p \mathrm{H}=7.5)$ and succinimidyl 3-azidopropanoate $(2.54 \mathrm{mg}, 12 \mu \mathrm{mol})$ in DMSO $(500 \mu \mathrm{L})$. The solution was mixed thoroughly and reacted in the dark for $3 \mathrm{~h}$. The solution was then loaded onto a strong cation exchange spin column (Thermo Fisher). The column was washed with $25 \mathrm{mM}$ ammonium acetate $(2 \times 400 \mu \mathrm{L})$ and eluted with $2 \mathrm{M}$ ammonium acetate. The eluent was concentrated in a vacuum chamber overnight, and the residue was dissolved in water to a final volume of $50 \mu \mathrm{L}$ to give an approx. $10 \mathrm{mM}$ stock solution. HRMS $\left(\mathrm{ESI}^{+}\right) \mathrm{m} / \mathrm{z}$ calcd 507.6567, found 507.6502 for $\mathrm{C}_{57} \mathrm{H}_{116} \mathrm{~N}_{39} \mathrm{O}_{11}{ }^{3+}\left(\mathrm{M}+3 \mathrm{H}^{+}\right)$; calcd 514.9840, found 514.9745 for $\mathrm{C}_{57} \mathrm{H}_{115} \mathrm{~N}_{39} \mathrm{NaO}_{11}{ }^{3+}\left(\mathrm{M}+2 \mathrm{H}^{+}+\mathrm{Na}^{+}\right)$. 


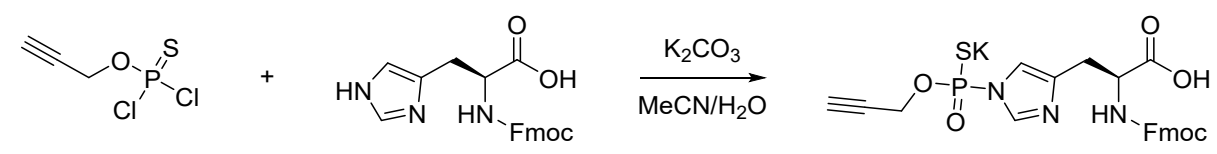

Potassium $\boldsymbol{O}$-propargyl $\left(\boldsymbol{N}^{2}\right.$-Fmoc-L-histidino)thiophosphate. Fmoc-His-OH $(0.20 \mathrm{~g}, 0.53 \mathrm{mmol})$ and $\mathrm{K}_{2} \mathrm{CO}_{3}(1.1 \mathrm{~g}, 8.0 \mathrm{mmol})$ was dissolved in 4:6 $\mathrm{H}_{2} \mathrm{O} / \mathrm{MeCN}(15 \mathrm{~mL})$. To this mixture was added TPAC $(0.30 \mathrm{~g}, 1.6 \mathrm{mmol})$ in $\mathrm{MeCN}(5 \mathrm{~mL})$ over $1 \mathrm{~h}$ under vigorous stirring. The mixture was further stirred for $2 \mathrm{~h}$ and the desired product was separated by RP-HPLC to give the product as an off-white solid $(0.22 \mathrm{~g}$, 75\%). This compound has the same retention time and $\mathrm{m} / \mathrm{z}$ on LC/MS as the product in Figure $\mathrm{S} 3 \mathrm{a} .{ }^{1} \mathrm{H}$ NMR (400 MHz, MeOD) $\delta 8.87(\mathrm{~s}, 1 \mathrm{H}), 7.78$ (d, J=7.4 Hz, 2H), 7.63 (d, J=7.2 Hz, 2H), 7.49 (s, 1H), $7.34(\mathrm{dt}, J=28.2,7.3 \mathrm{~Hz}, 4 \mathrm{H}), 4.68-4.58(\mathrm{~m}, 2 \mathrm{H}), 4.51(\mathrm{dd}, J=9.3,4.8 \mathrm{~Hz}, 1 \mathrm{H}), 4.37-4.28(\mathrm{~m}, 2 \mathrm{H})$, $4.20(\mathrm{t}, J=6.7 \mathrm{~Hz}, 1 \mathrm{H}), 3.27(\mathrm{~d}, J=4.7 \mathrm{~Hz}, 1 \mathrm{H}), 3.09(\mathrm{dd}, J=15.1,9.7 \mathrm{~Hz}, 1 \mathrm{H}), 2.76-2.66(\mathrm{~m}, 1 \mathrm{H})$. ${ }^{31} \mathrm{P} \mathrm{NMR}(162 \mathrm{MHz}, \mathrm{MeOD}) \delta$ 49.01. HRMS $\left(\mathrm{ESI}^{+}\right) \mathrm{m} / \mathrm{z}$ calcd 512.1040, found 512.1092 for $\mathrm{C}_{24} \mathrm{H}_{23} \mathrm{~N}_{3} \mathrm{O}_{6} \mathrm{PS}^{+}\left(\mathrm{M}+\mathrm{H}^{+}\right)$. 
NMR Spectra

${ }^{1} \mathrm{H}$ NMR of 4 (TPAC) $\left(\mathrm{CDCl}_{3}, 400 \mathrm{MHz}\right)$

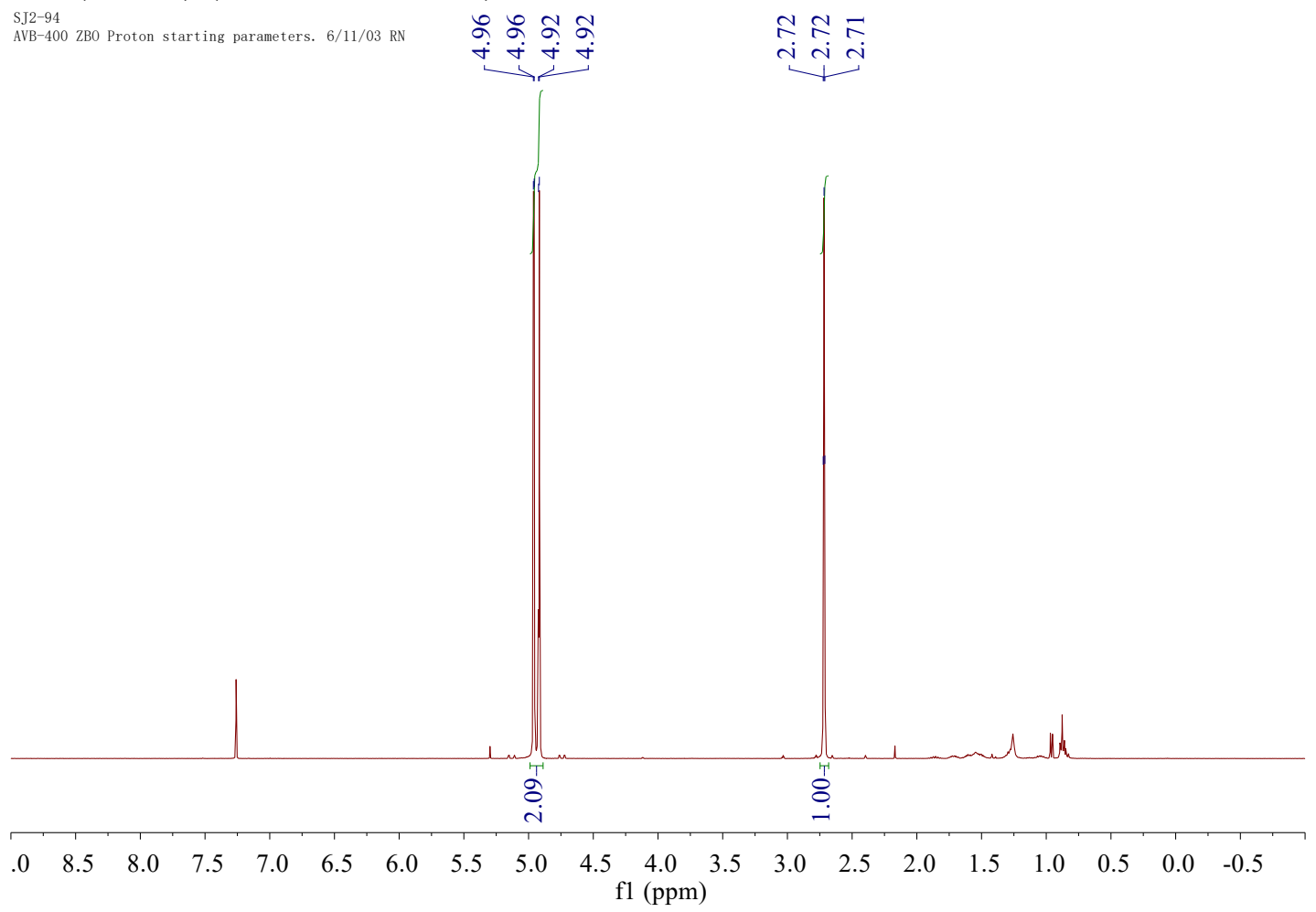

${ }^{13} \mathrm{C}$ NMR of 4 (TPAC) $\left(\mathrm{CDCl}_{3}, 101 \mathrm{MHz}\right)$

SJ2-94
AVB-400 ZBO Carbon Starting paramters 6/11/03 RN

กิ

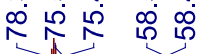

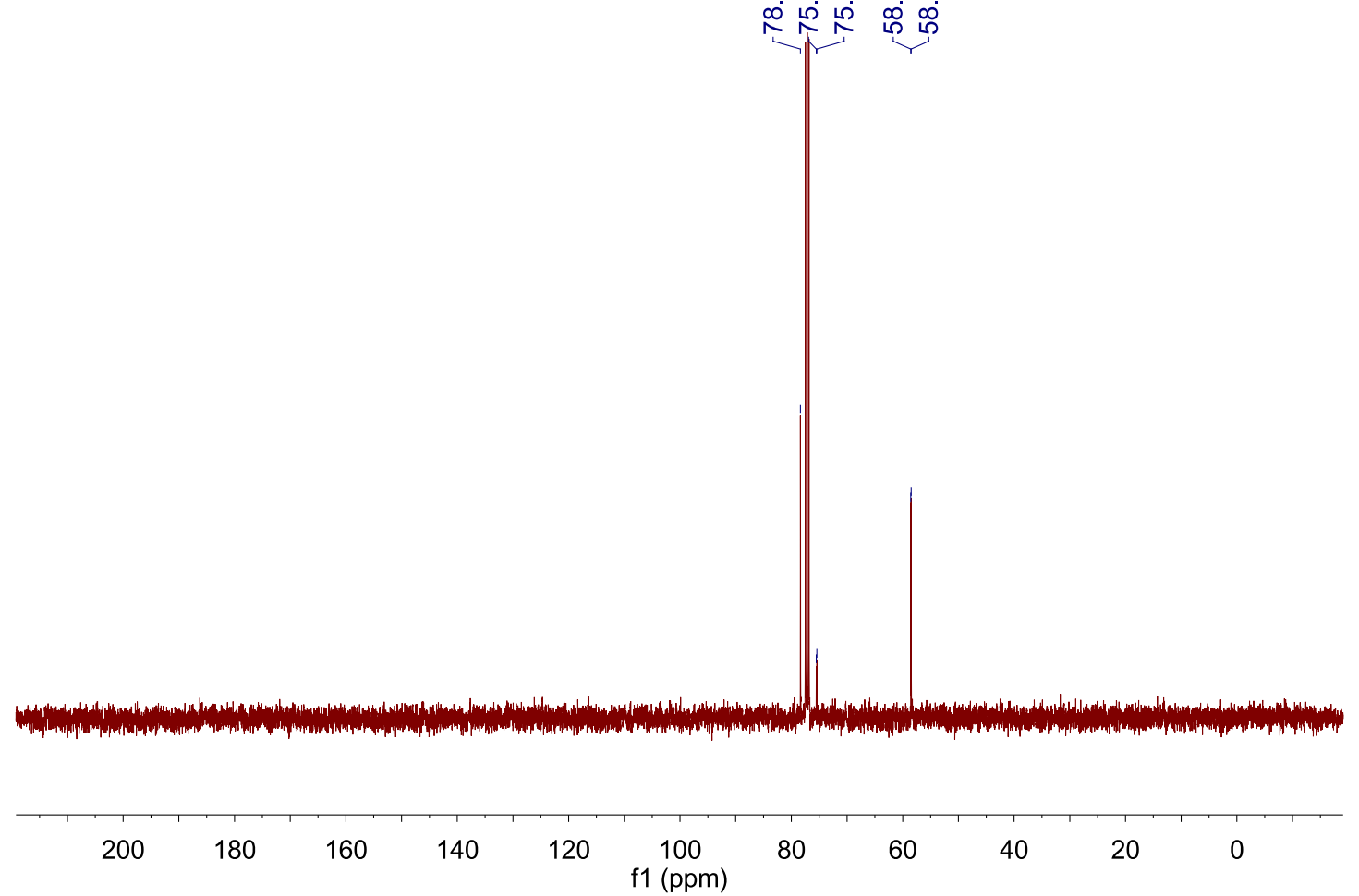


${ }^{31} \mathrm{P}$ NMR of 4 (TPAC) $\left(\mathrm{CDCl}_{3}, 162 \mathrm{MHz}\right)$

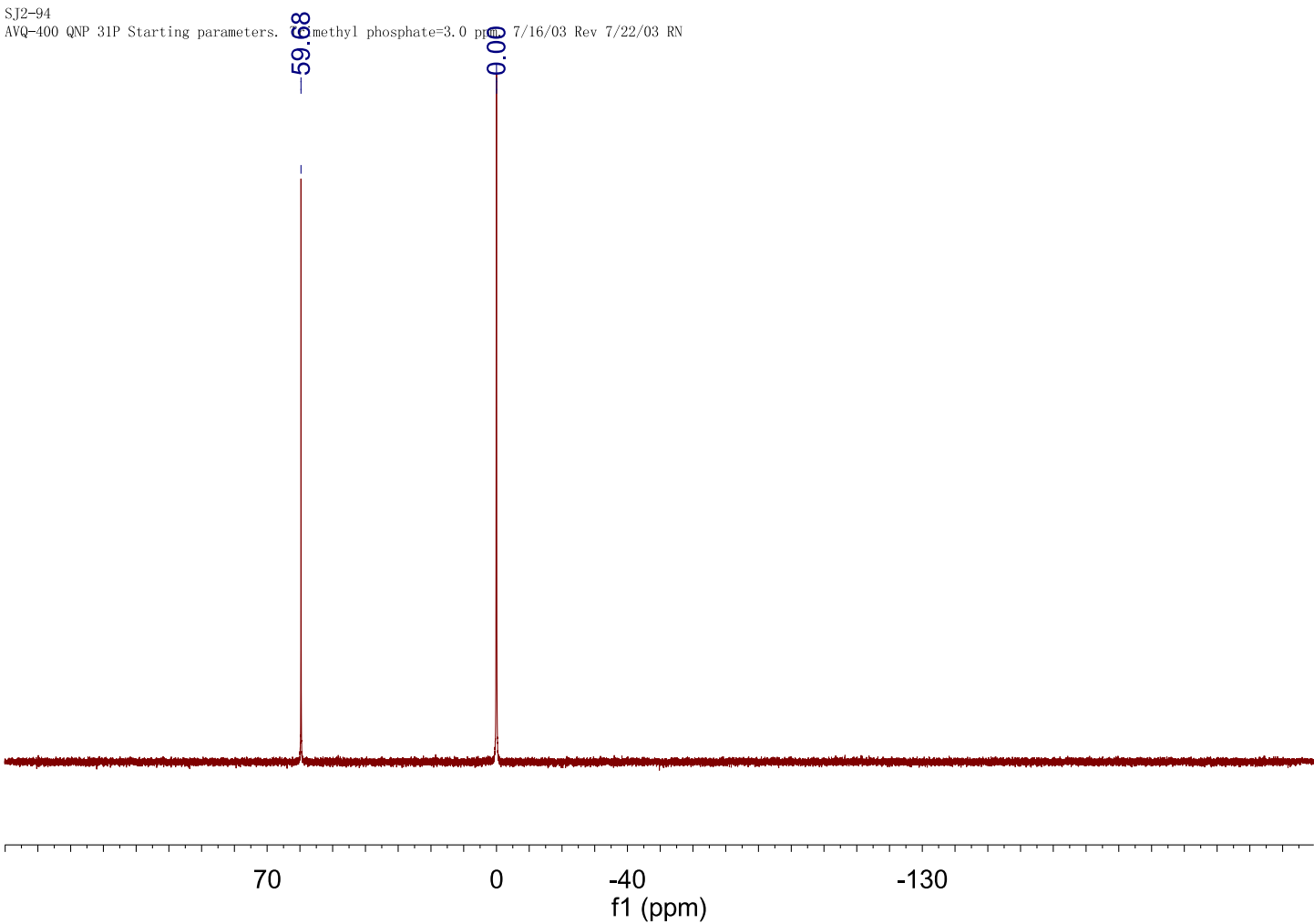


${ }^{1} \mathrm{H}$ NMR of 1 (MeOD, $\left.400 \mathrm{MHz}\right)$

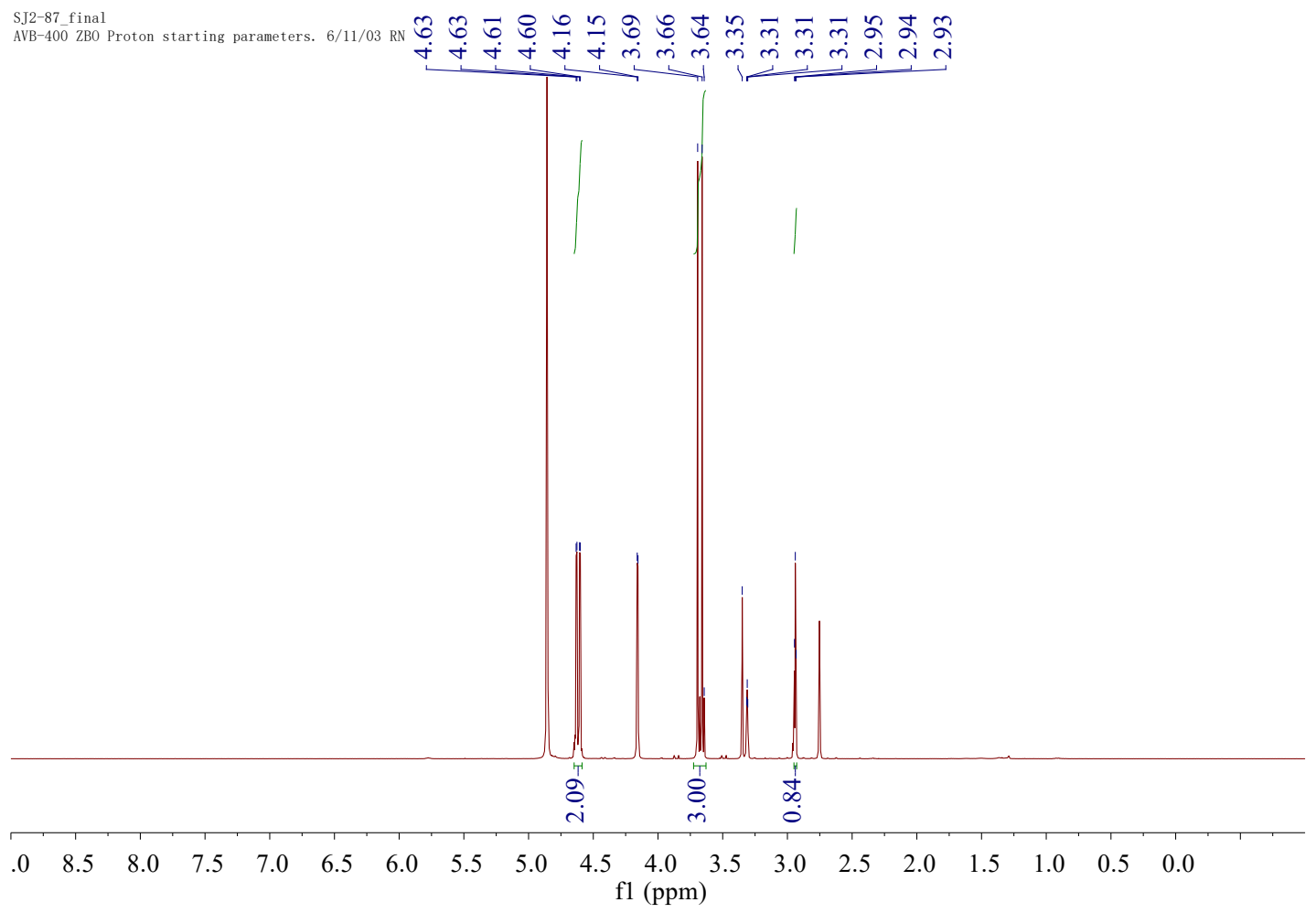

${ }^{13} \mathrm{C}$ NMR of TPAC (MeOD, $\left.101 \mathrm{MHz}\right)$

SJ2-87_final

AVB-400 ZB0 Carbon Starting paramters 6/11/03 RN

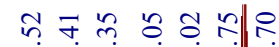

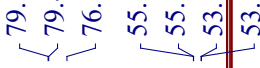

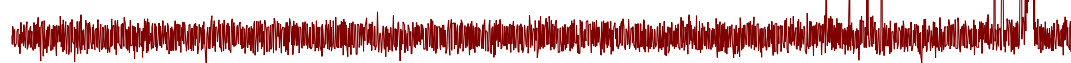

\begin{tabular}{|c|c|c|c|c|c|c|c|c|c|c|c|}
\hline 20 & 200 & 180 & 160 & 140 & 120 & $\begin{array}{c}100 \\
1(\mathrm{ppm})\end{array}$ & 80 & 60 & 40 & 20 & 0 \\
\hline
\end{tabular}


${ }^{31} \mathrm{P} \mathrm{NMR}$ of $\mathbf{1}\left(\mathrm{CDCl}_{3}, 162 \mathrm{MHz}\right)$

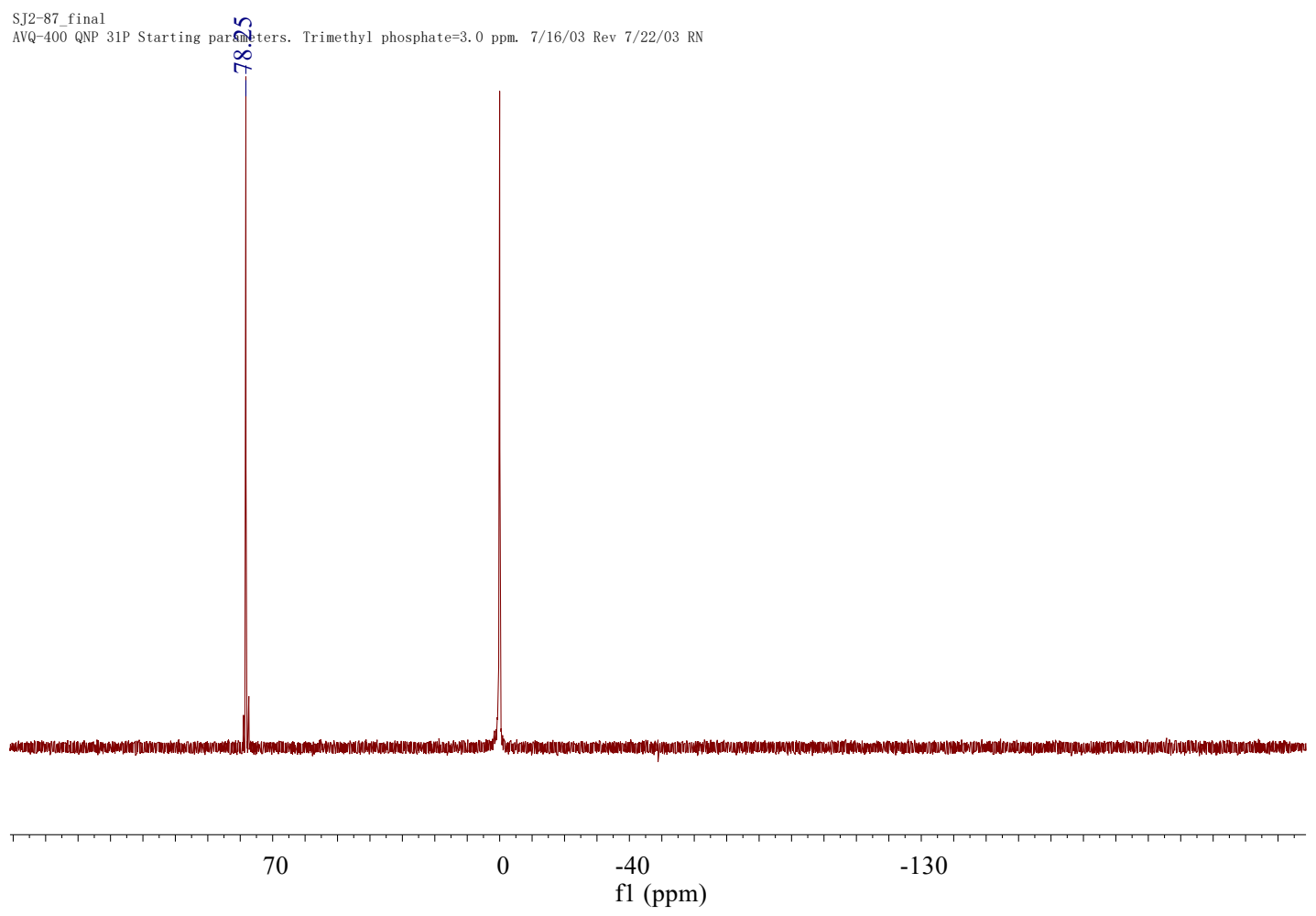


${ }^{1} \mathrm{H} \mathrm{NMR}$ of $2\left(\mathrm{CDCl}_{3}, 400 \mathrm{MHz}\right)$

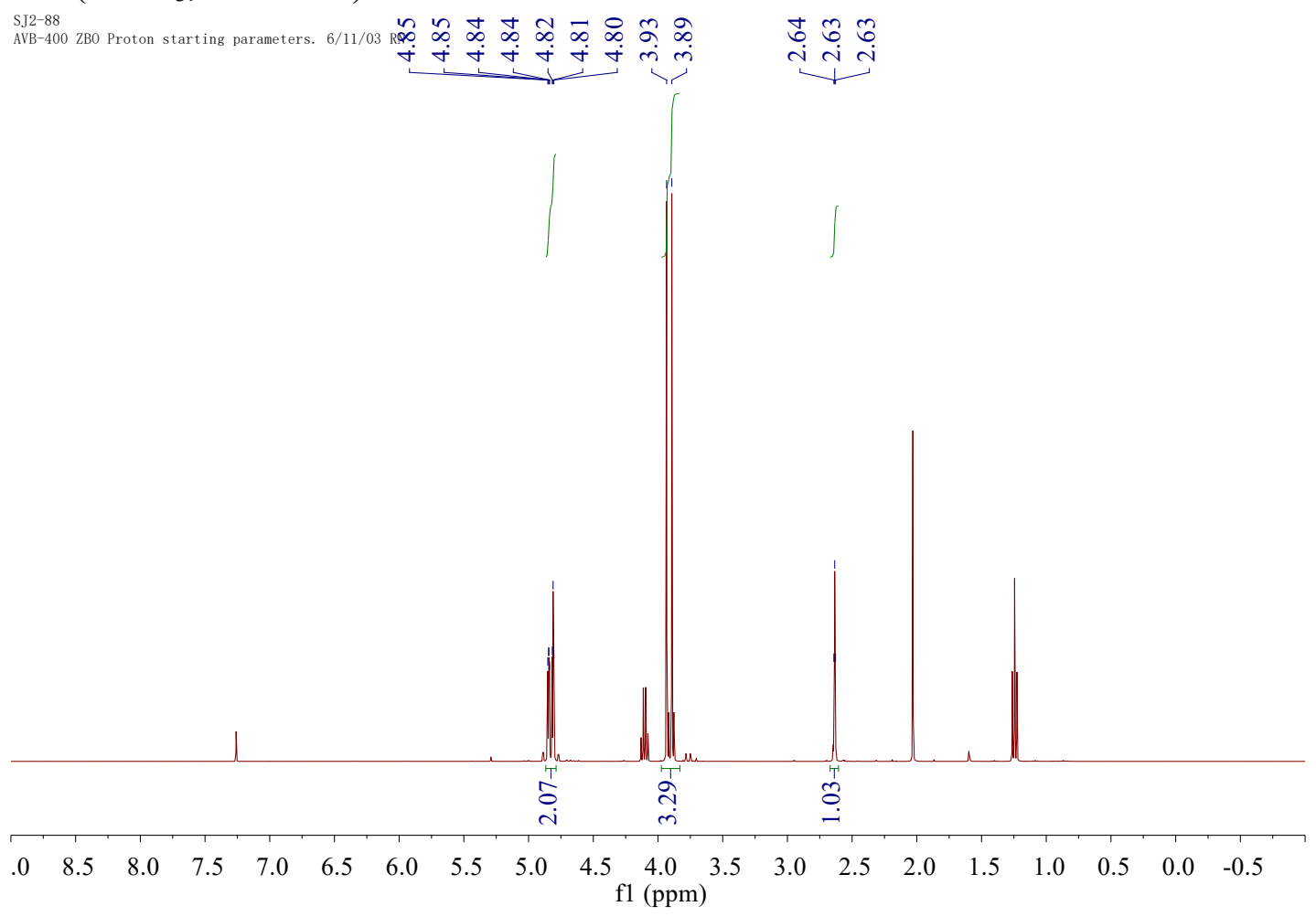

${ }^{13} \mathrm{C}$ NMR of $2\left(\mathrm{CDCl}_{3}, 101 \mathrm{MHz}\right)$

SJ2-88 3 arbon Starting paramters 6/11/03 RN

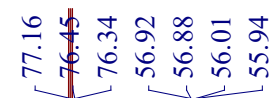

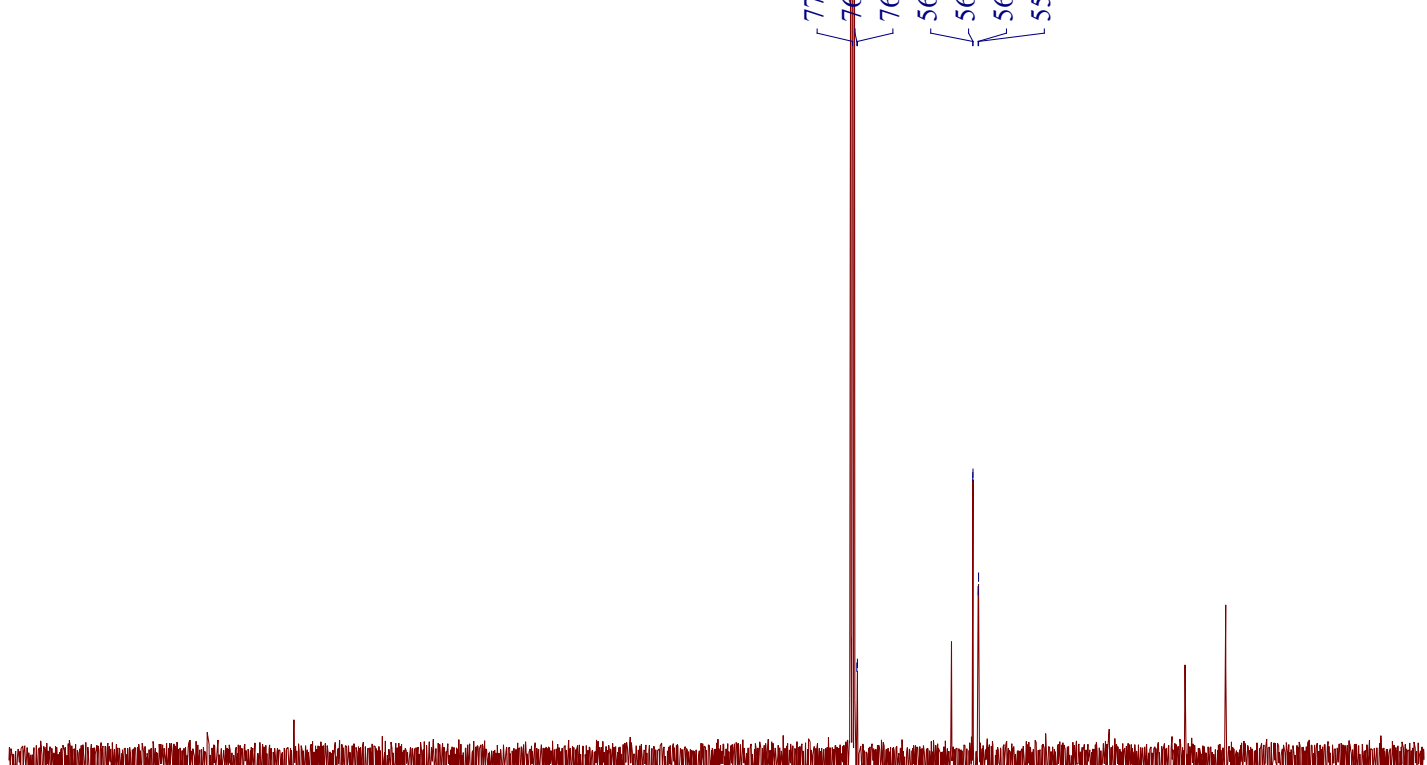

\begin{tabular}{|c|c|c|c|c|c|c|c|c|c|c|}
\hline 200 & 180 & 160 & 140 & 120 & $\begin{array}{c}100 \\
\mathrm{f} 1(\mathrm{ppm})\end{array}$ & 80 & 60 & 40 & 20 & 0 \\
\hline
\end{tabular}


${ }^{31} \mathrm{P}$ NMR of $2\left(\mathrm{CDCl}_{3}, 162 \mathrm{MHz}\right)$

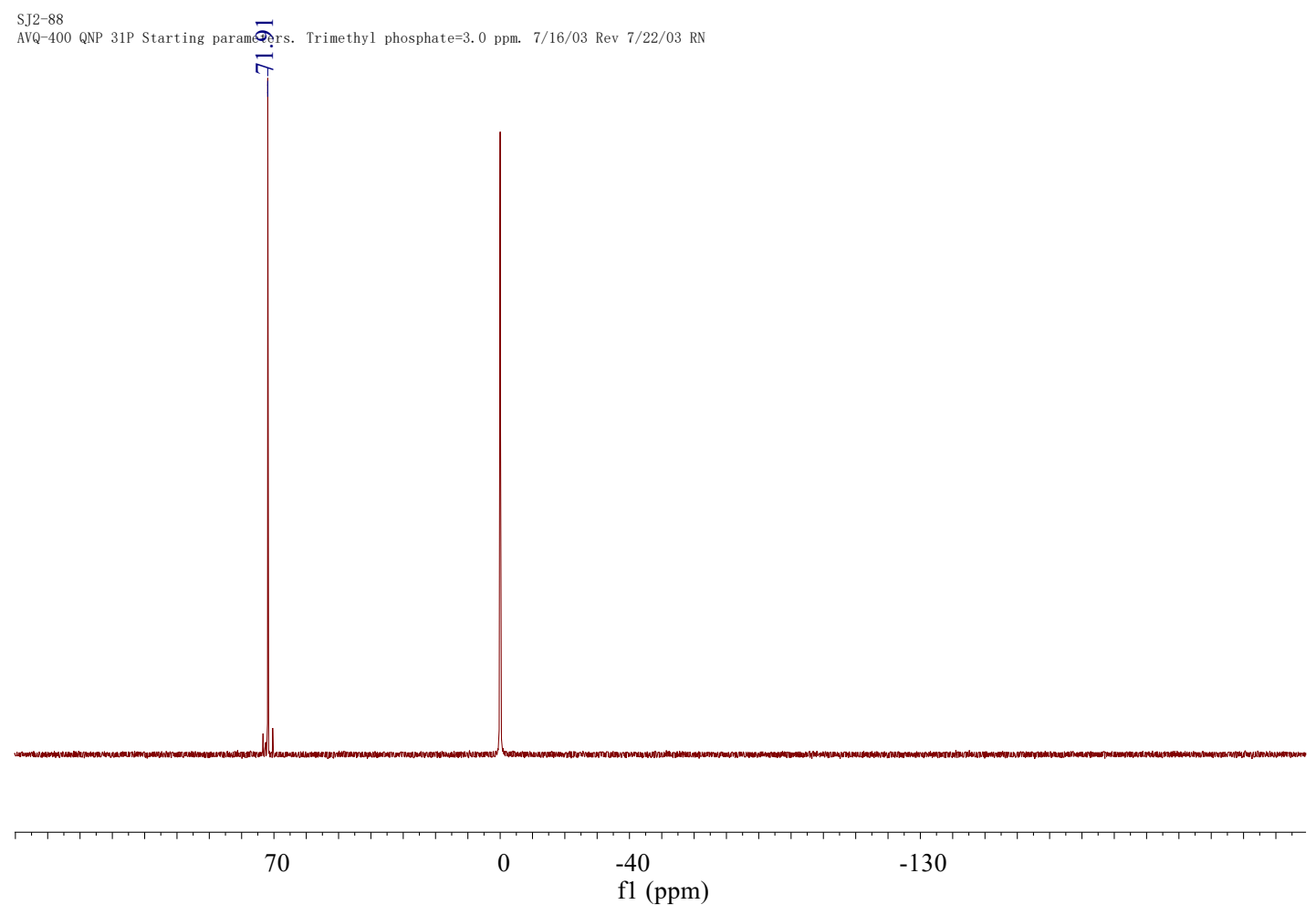


${ }^{1} \mathrm{H} \mathrm{NMR}$ of $3\left(\mathrm{CDCl}_{3}, 400 \mathrm{MHz}\right)$

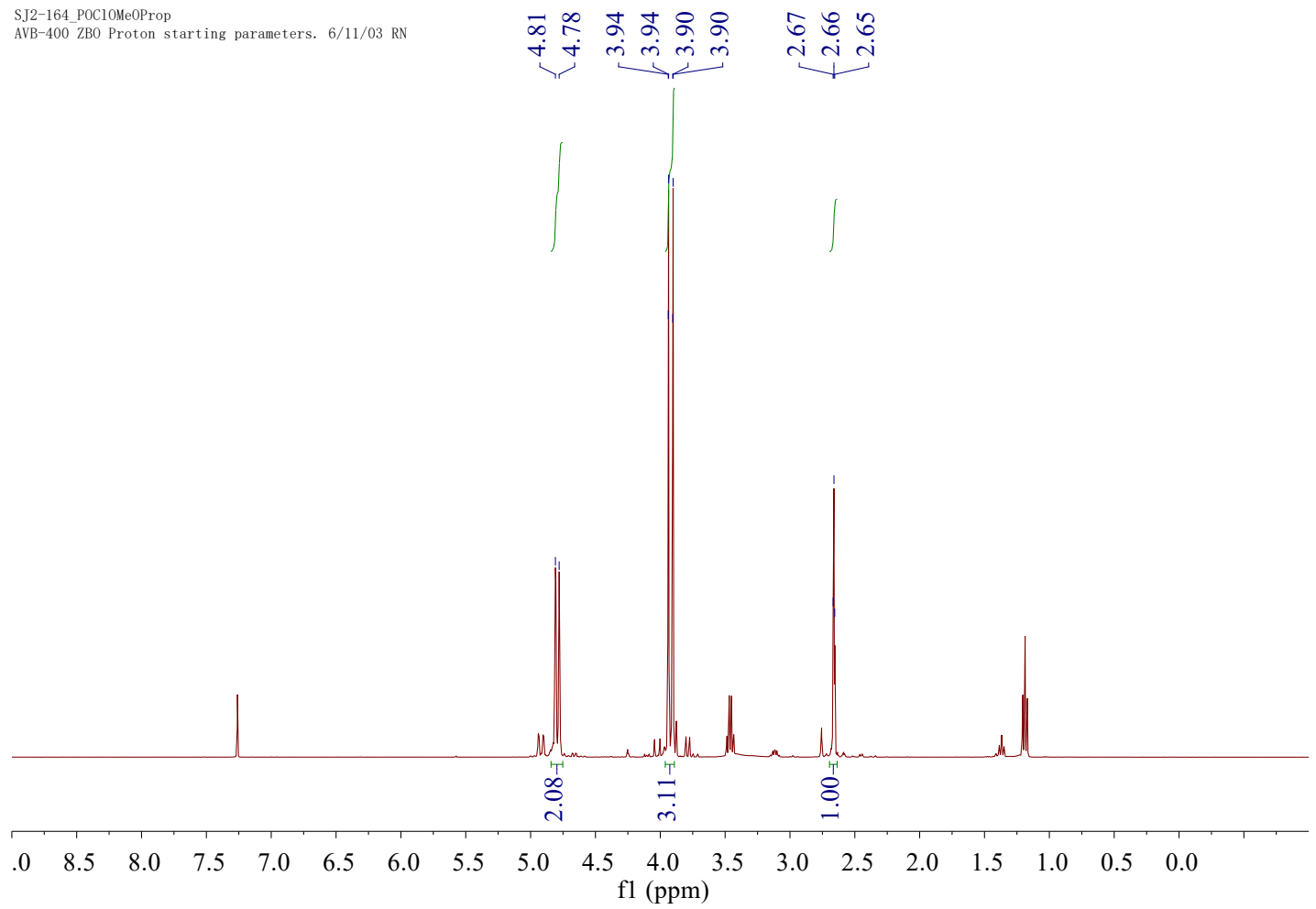

${ }^{13} \mathrm{C} \mathrm{NMR}$ of $3\left(\mathrm{CDCl}_{3}, 101 \mathrm{MHz}\right)$

SJ2-164_POC10Me0Prop

AVB-400 ZBO Carbon Starting paramters 6/11/03 RN

ส예

政 in in

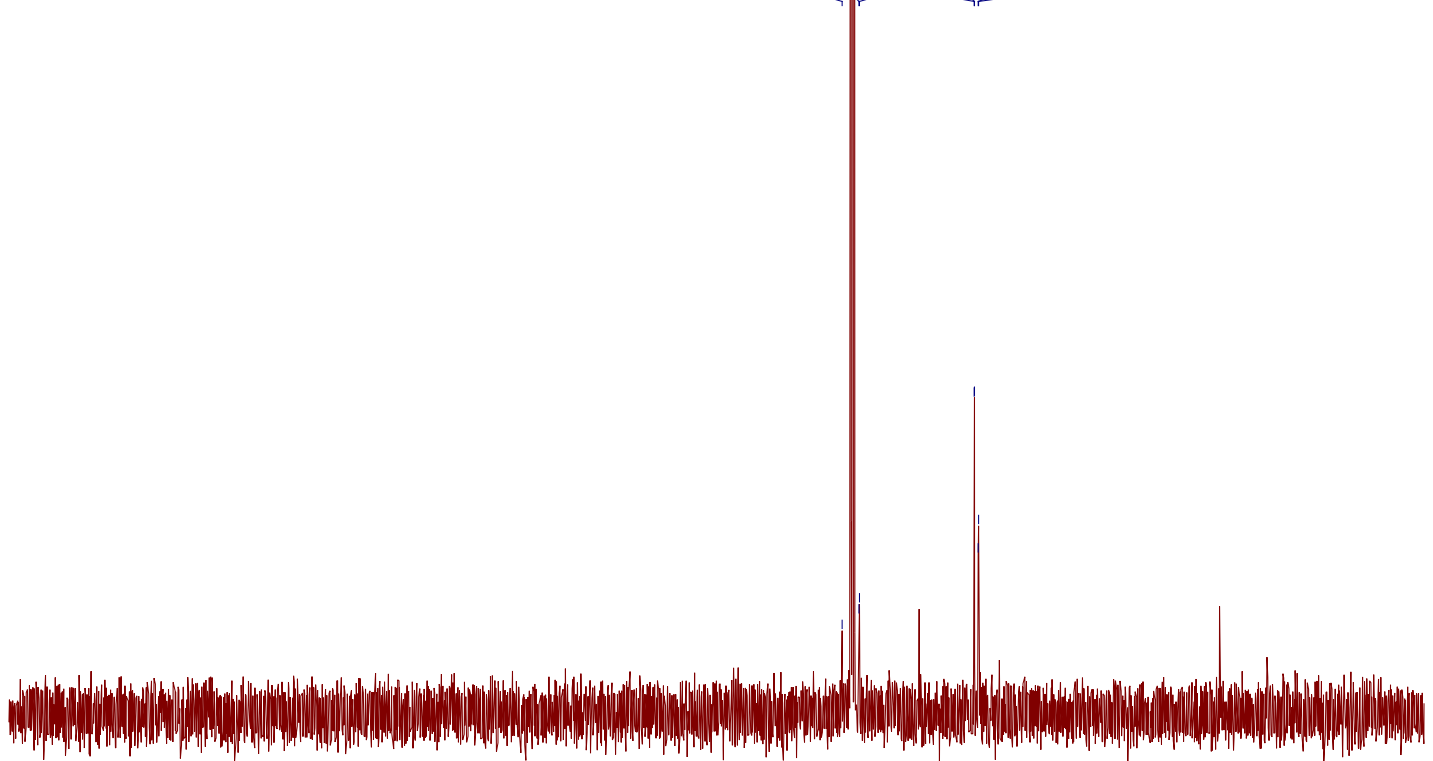

200

180

160

140

120

100

80

60

40

20

0 
${ }^{31} \mathrm{P} \mathrm{NMR}$ of $\mathbf{3}\left(\mathrm{CDCl}_{3}, 162 \mathrm{MHz}\right)$

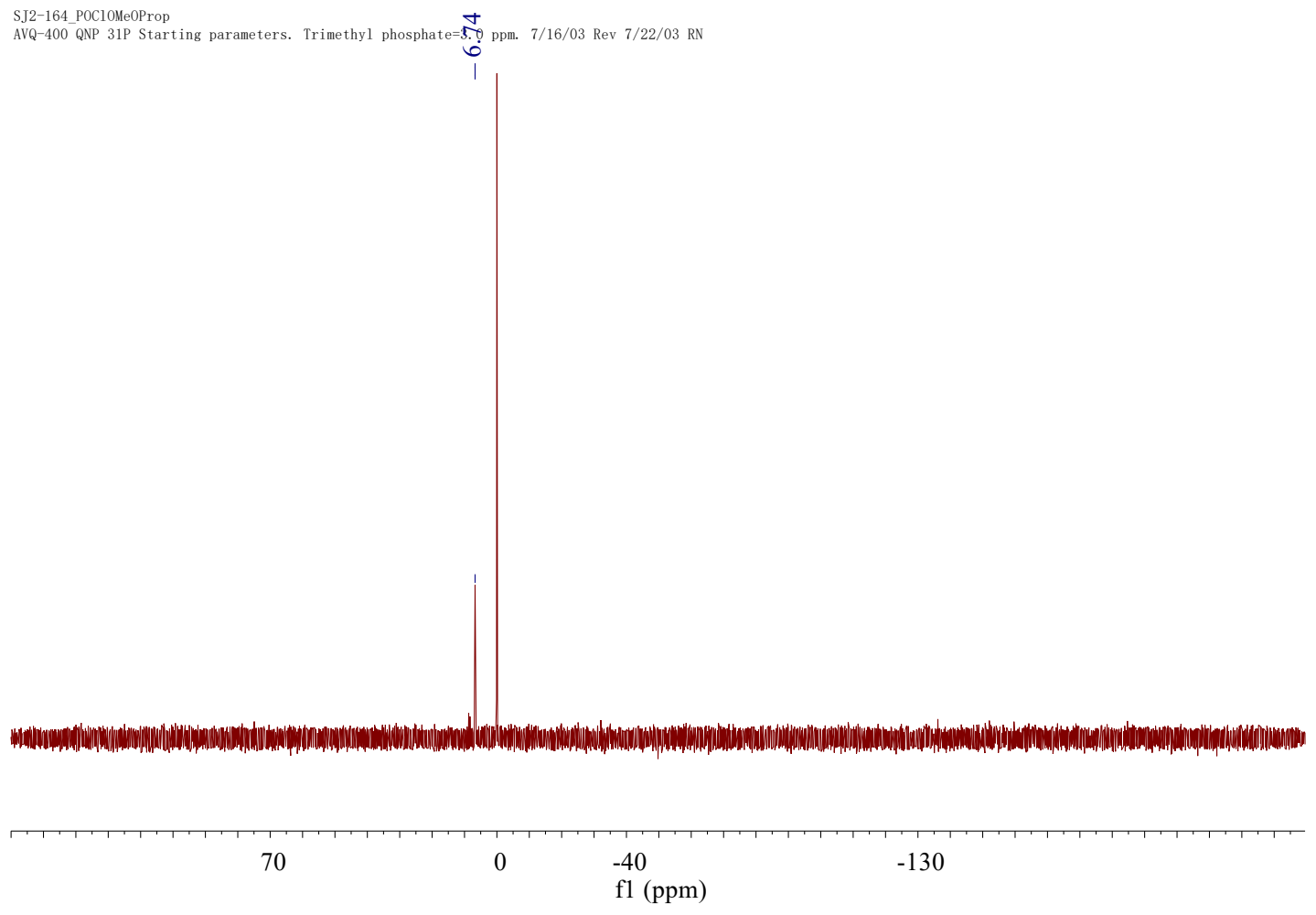


${ }^{1} \mathrm{H} \mathrm{NMR}$ of $5\left(\mathrm{CDCl}_{3}, 400 \mathrm{MHz}\right)$

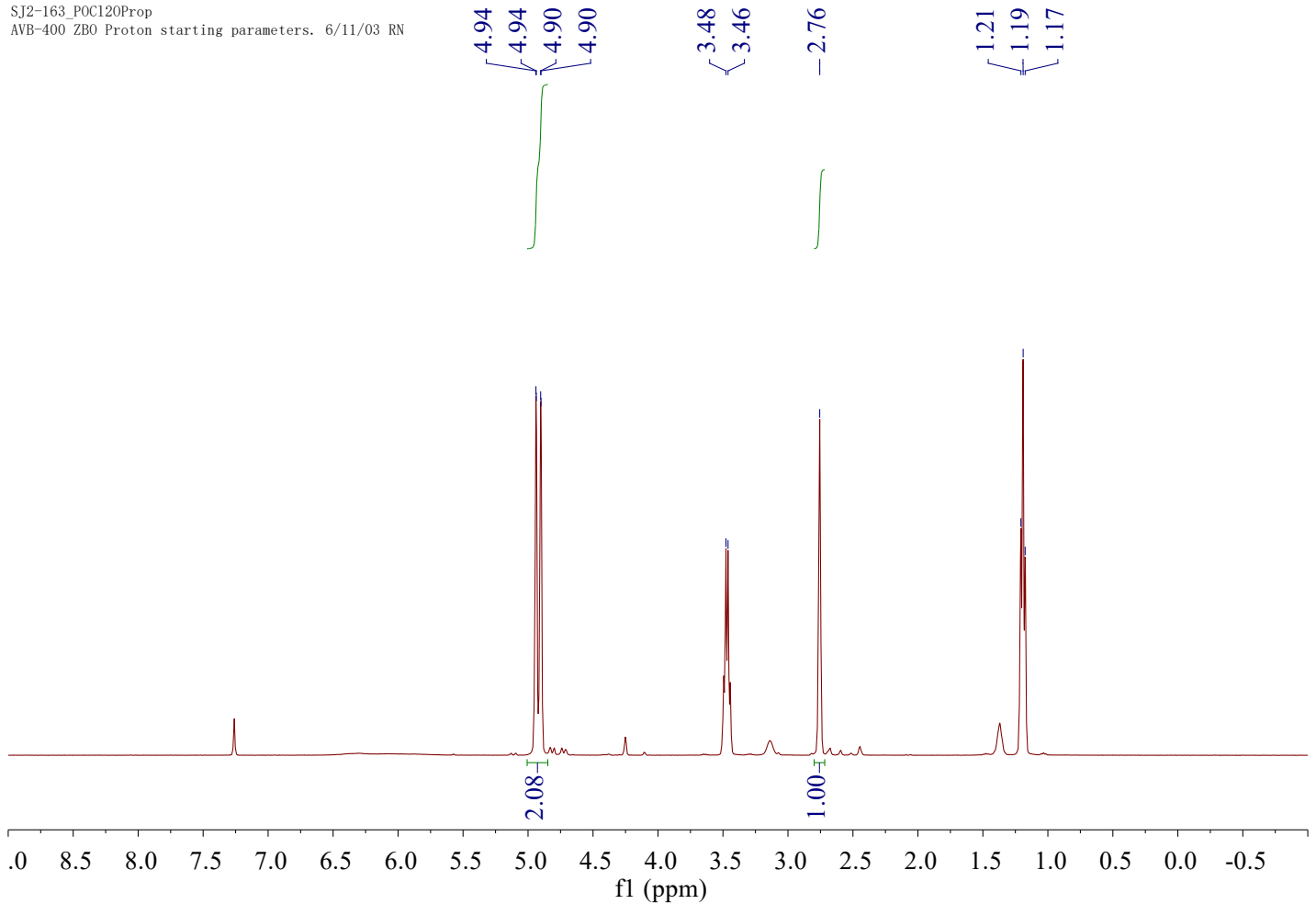

${ }^{13} \mathrm{C} \mathrm{NMR}$ of $5\left(\mathrm{CDCl}_{3}, 101 \mathrm{MHz}\right)$

SJ2-163_POC120Prop

AVB-400 ZB0 Carbon Starting paramters 6/11/03 RN

જ̆

$\underbrace{\infty}_{\substack{n \\ 0}}$

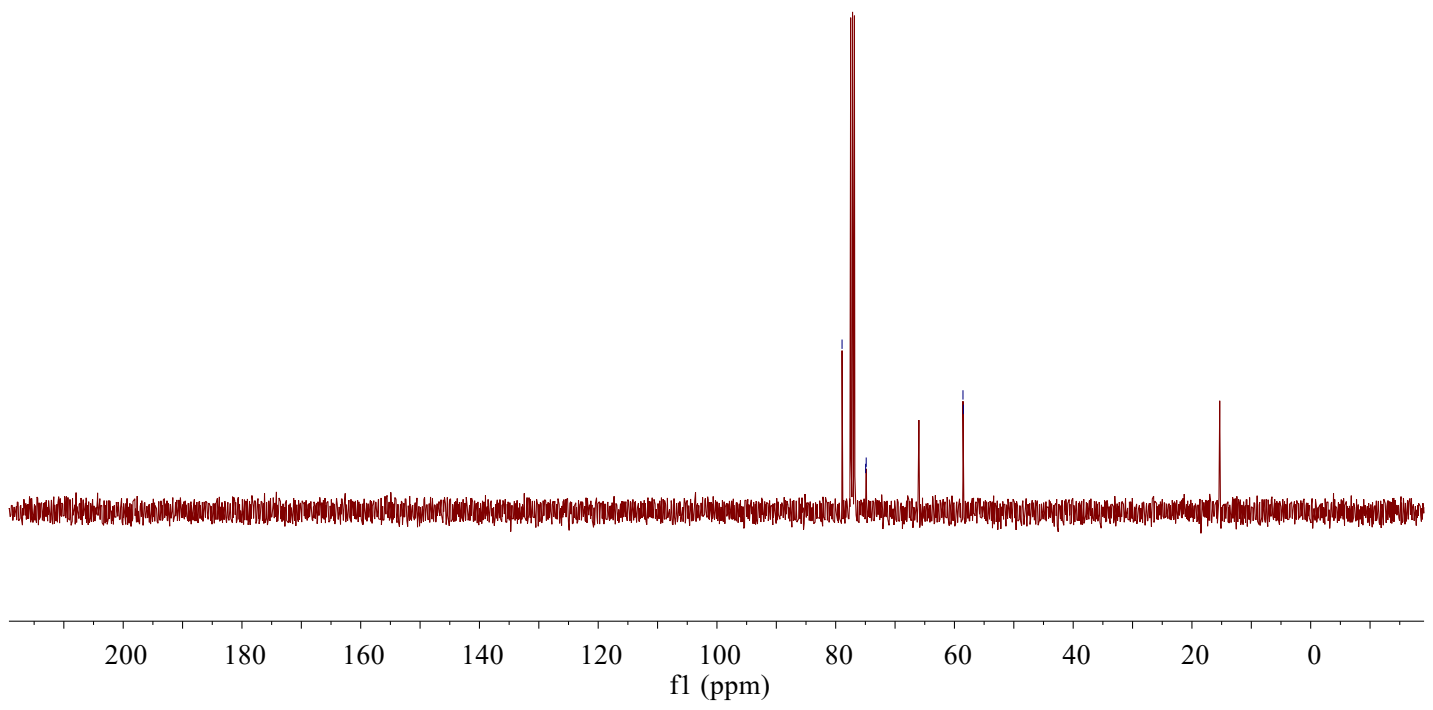


${ }^{31} \mathrm{P} \mathrm{NMR}$ of $\mathbf{5}\left(\mathrm{CDCl}_{3}, 162 \mathrm{MHz}\right)$

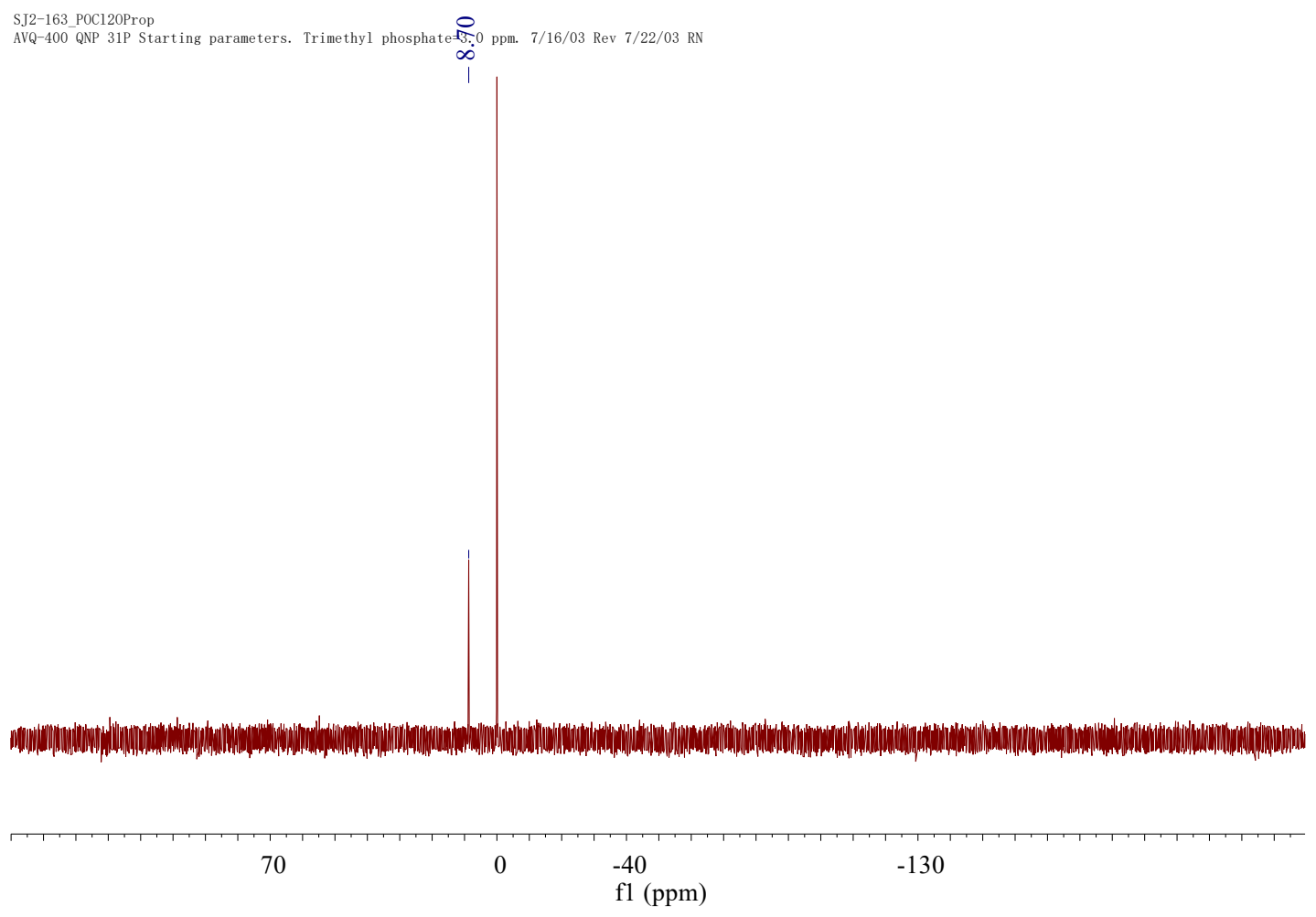


${ }^{1} \mathrm{H}$ NMR of 6 ( $d_{6}$-acetone, $\left.400 \mathrm{MHz}\right)$

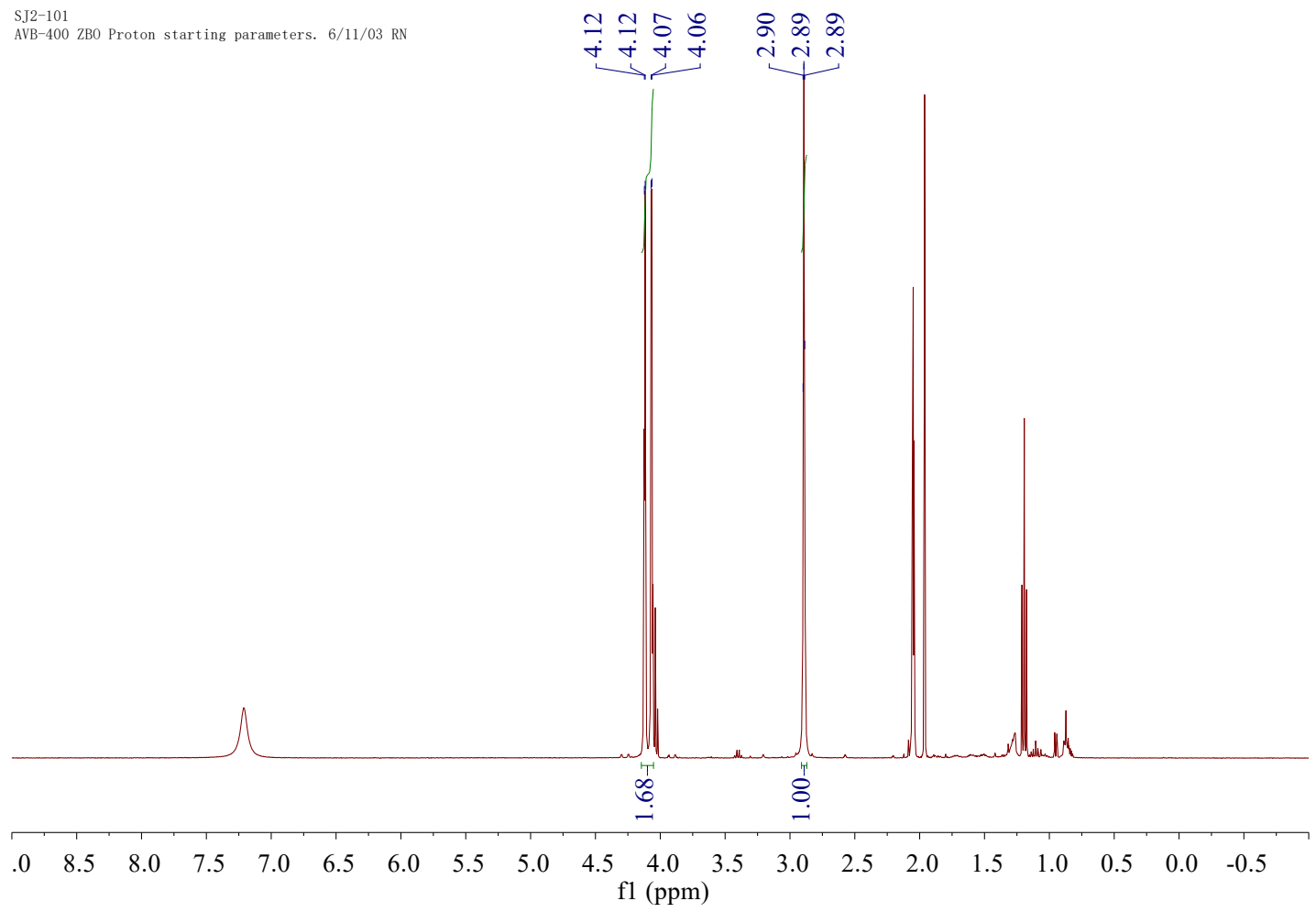

${ }^{13} \mathrm{C}$ NMR of $6\left(d_{6}\right.$-acetone, $\left.101 \mathrm{MHz}\right)$

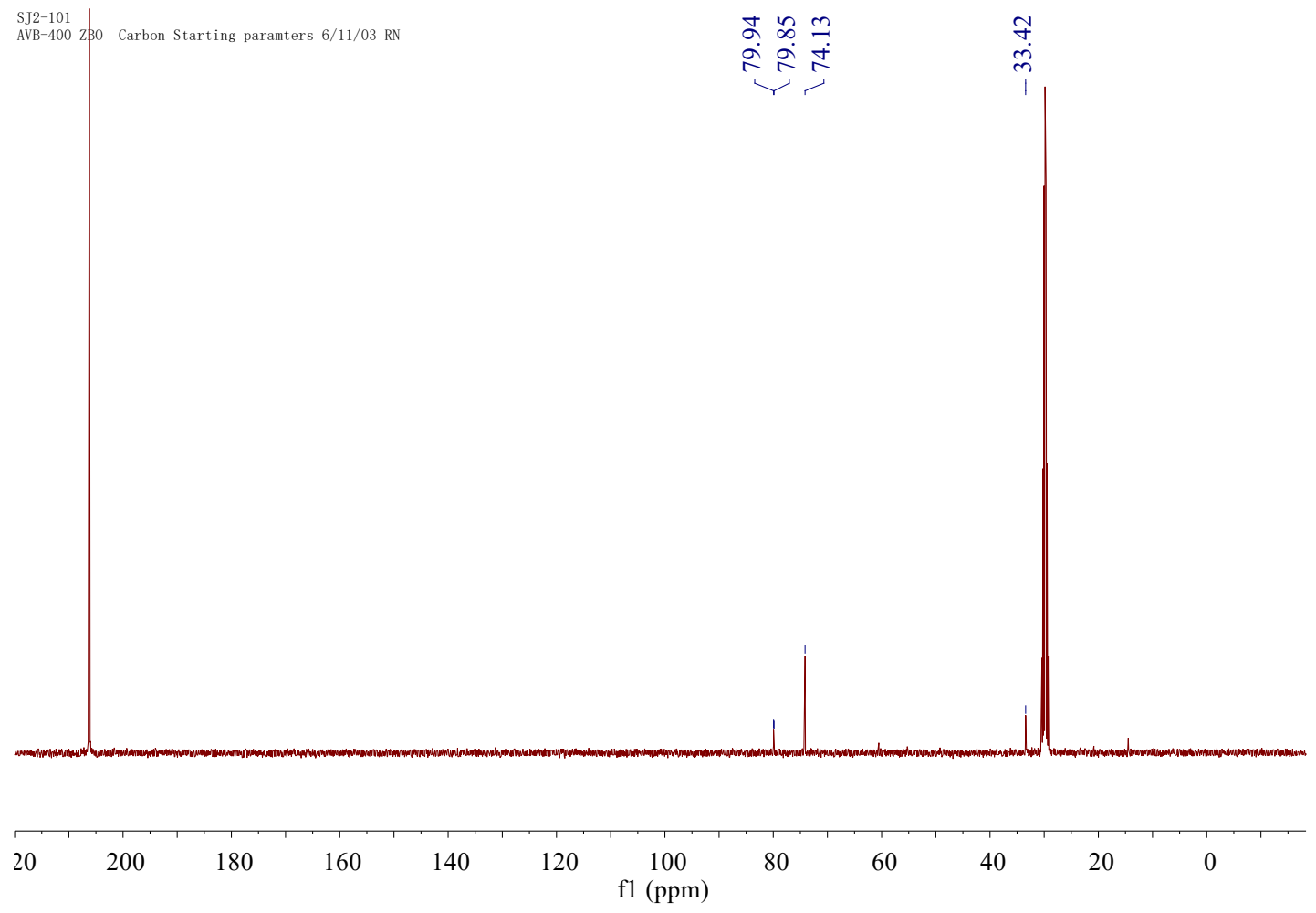


${ }^{31} \mathrm{P}$ NMR of 6 ( $d_{6}$-acetone, $\left.162 \mathrm{MHz}\right)$

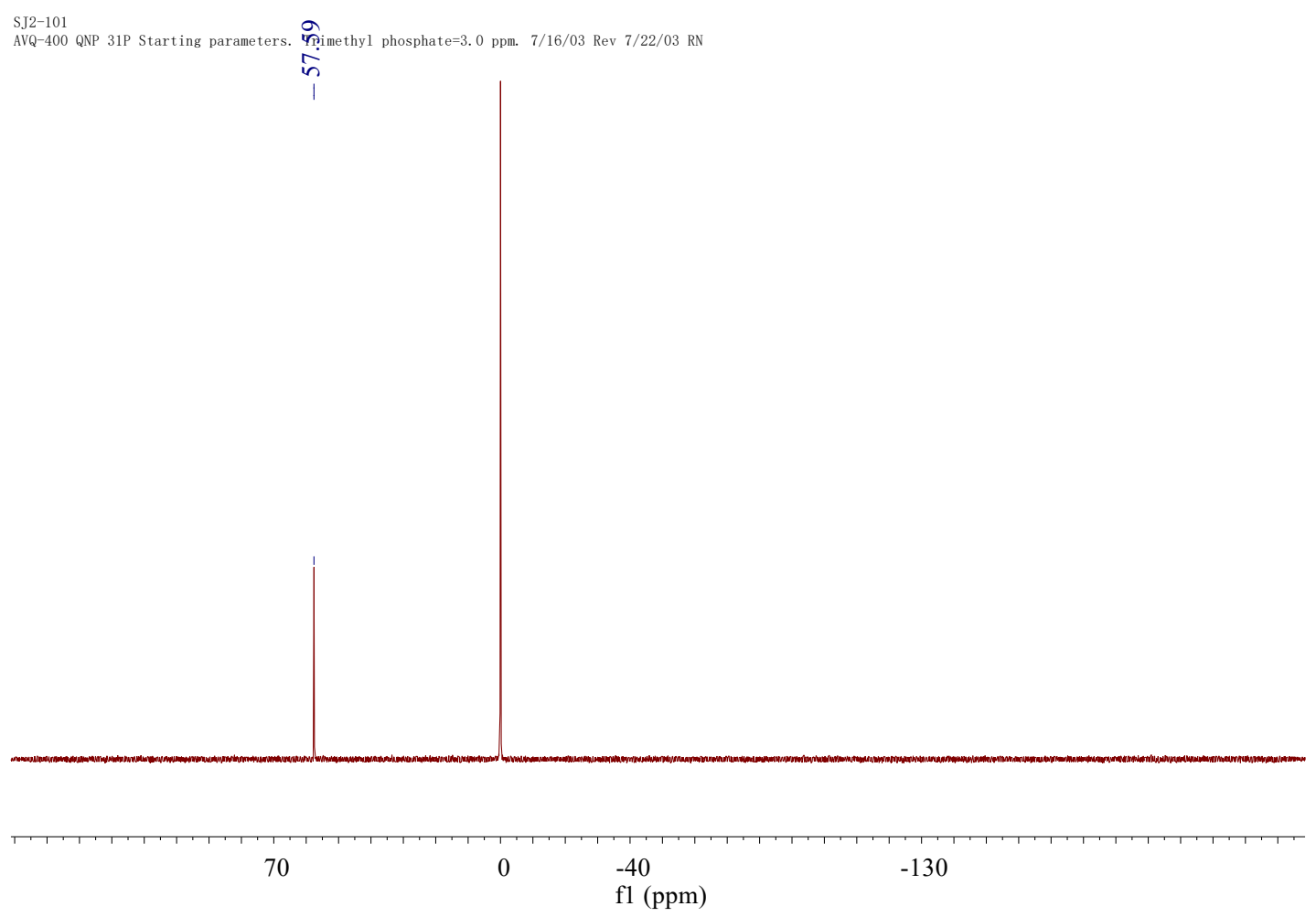

${ }^{1} \mathrm{H} \mathrm{NMR} \mathrm{of} 7\left(\mathrm{CDCl}_{3}, 600 \mathrm{MHz}\right)$

SJ2-115_down_PSC12
AV-600 ZBo proton starting parameters 11/16/08 RN

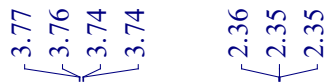

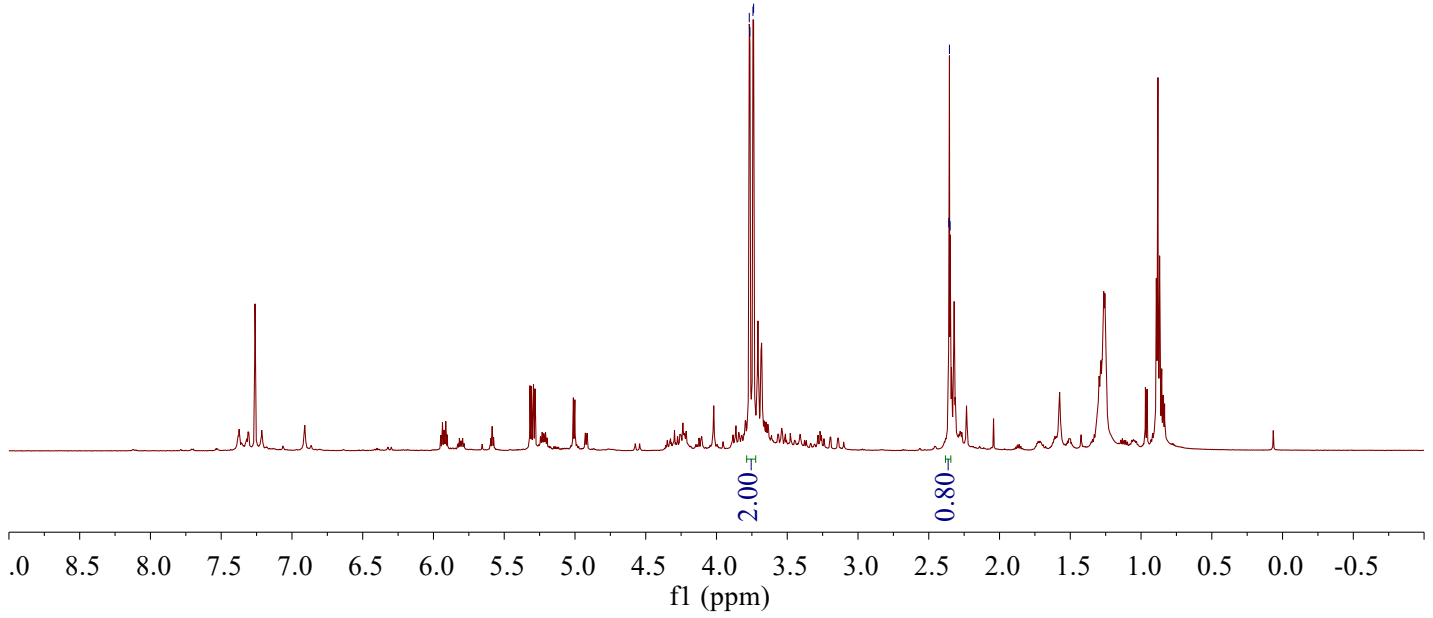


${ }^{1} \mathrm{H} \mathrm{NMR}$ of $8\left(\mathrm{CDCl}_{3}, 400 \mathrm{MHz}\right)$

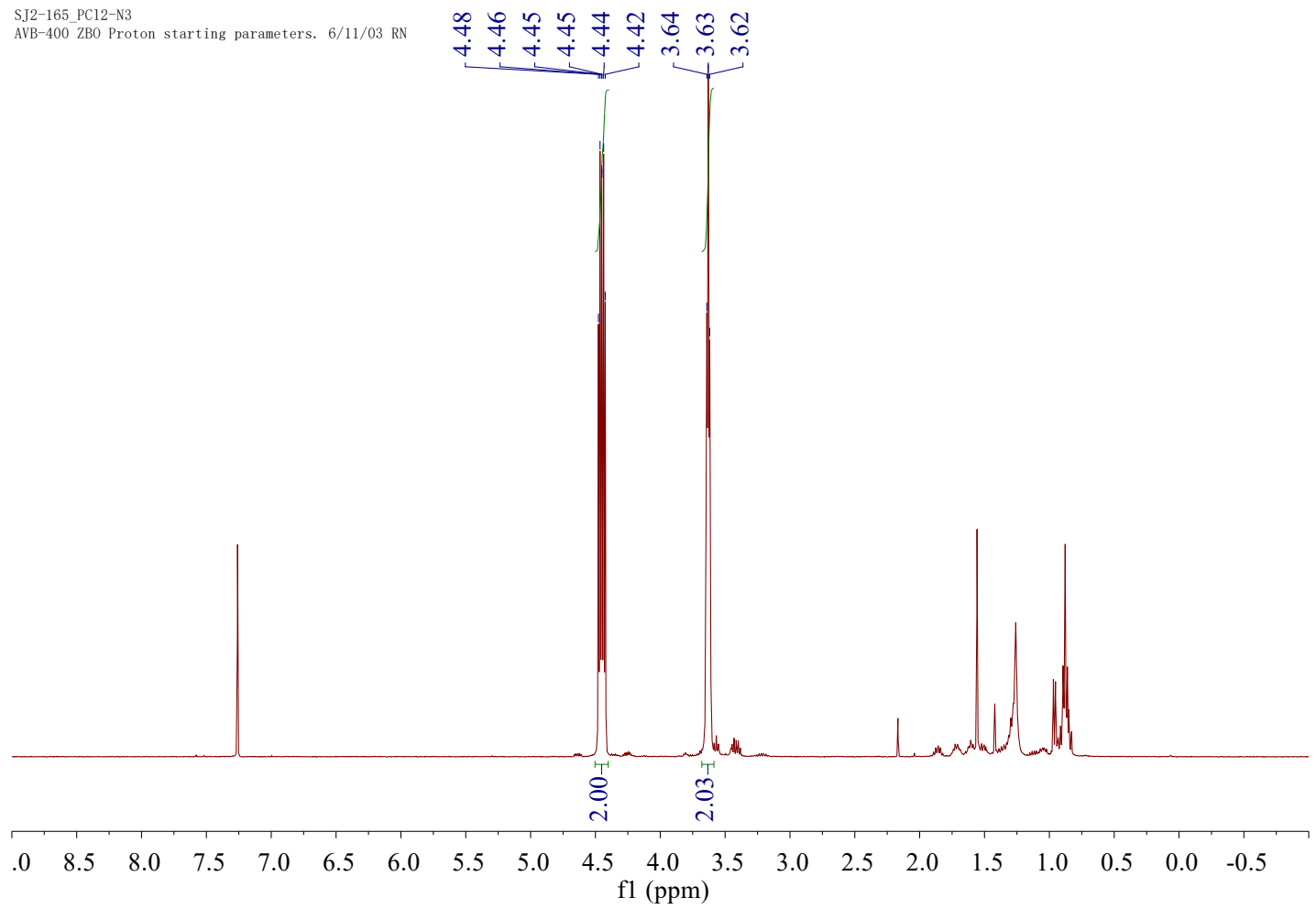

${ }^{13} \mathrm{C} \mathrm{NMR} \mathrm{of} 8\left(\mathrm{CDCl}_{3}, 101 \mathrm{MHz}\right)$

SJ2-165_PC12-N3

AVB-400 2B0 Proton starting parameters. 6/11/03 RV

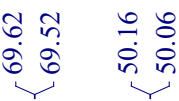

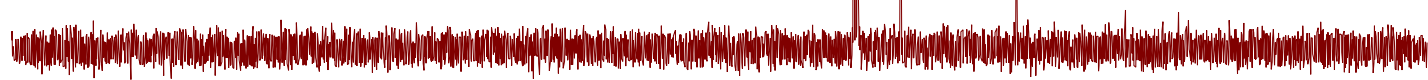

200

180

160

140

120

100

80

60

40

20

0 
${ }^{31} \mathrm{P} \mathrm{NMR}$ of $8\left(\mathrm{CDCl}_{3}, 162 \mathrm{MHz}\right)$

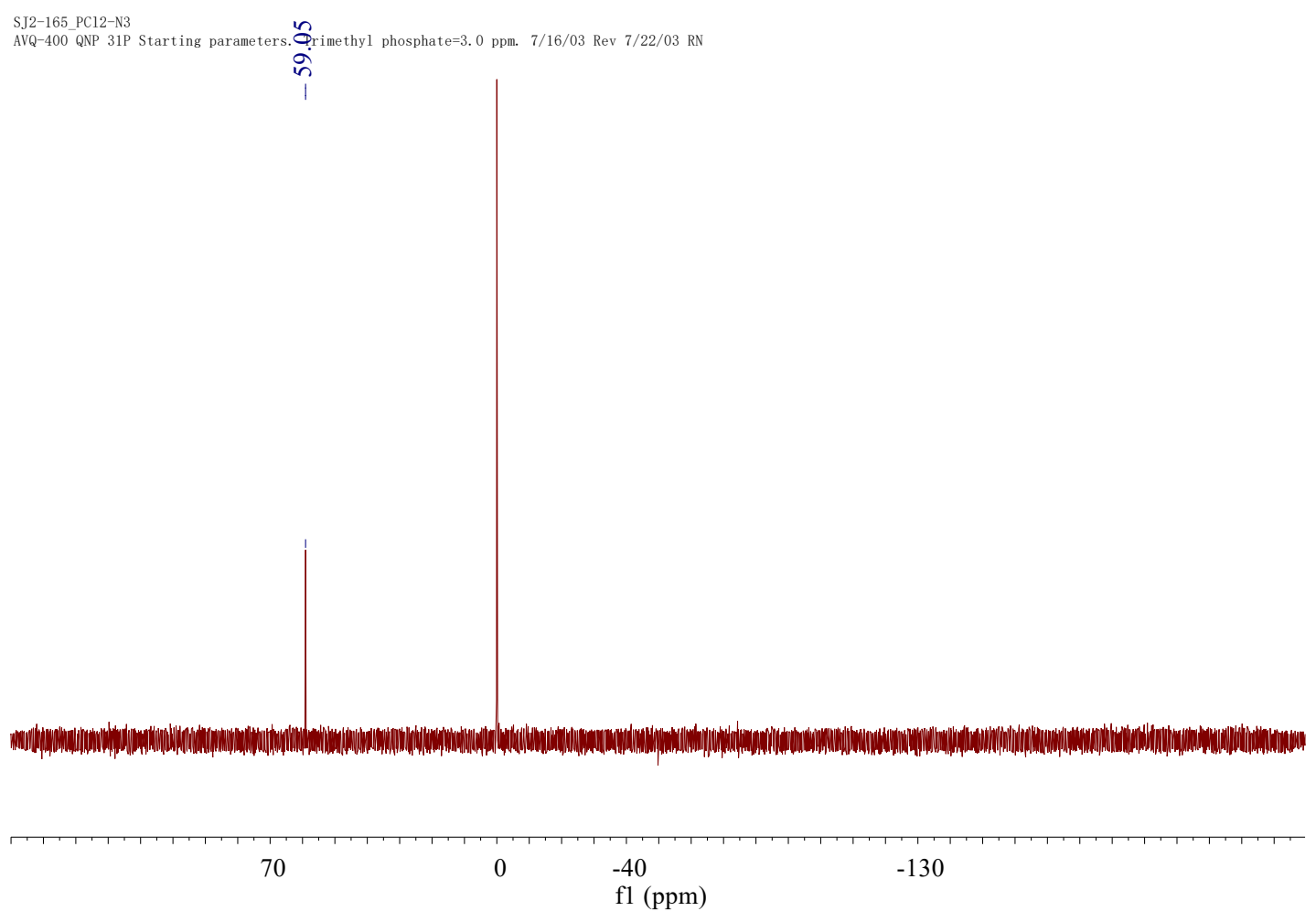


${ }^{1} \mathrm{H} \mathrm{NMR}$ of $9\left(\mathrm{CDCl}_{3}, 400 \mathrm{MHz}\right)$

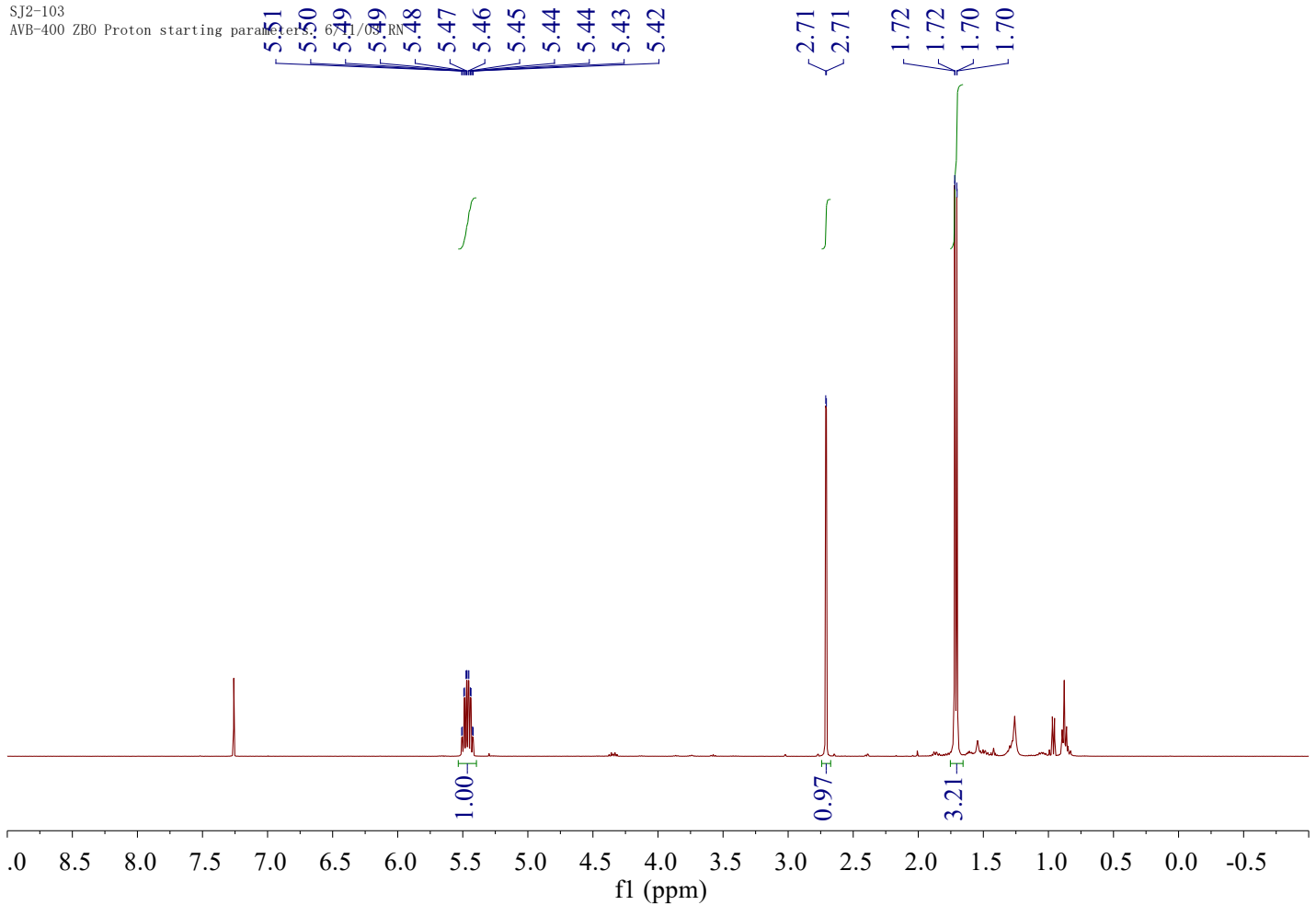

${ }^{13} \mathrm{C} \mathrm{NMR} \mathrm{of} 9\left(\mathrm{CDCl}_{3}, 101 \mathrm{MHz}\right)$

SJ2-103 7BO Carbon Starting paramters 6/11/03 RN

ลุ สุ ชั กุ

จ

$\longrightarrow$ 计

$\overrightarrow{4} \pm$

กั กั

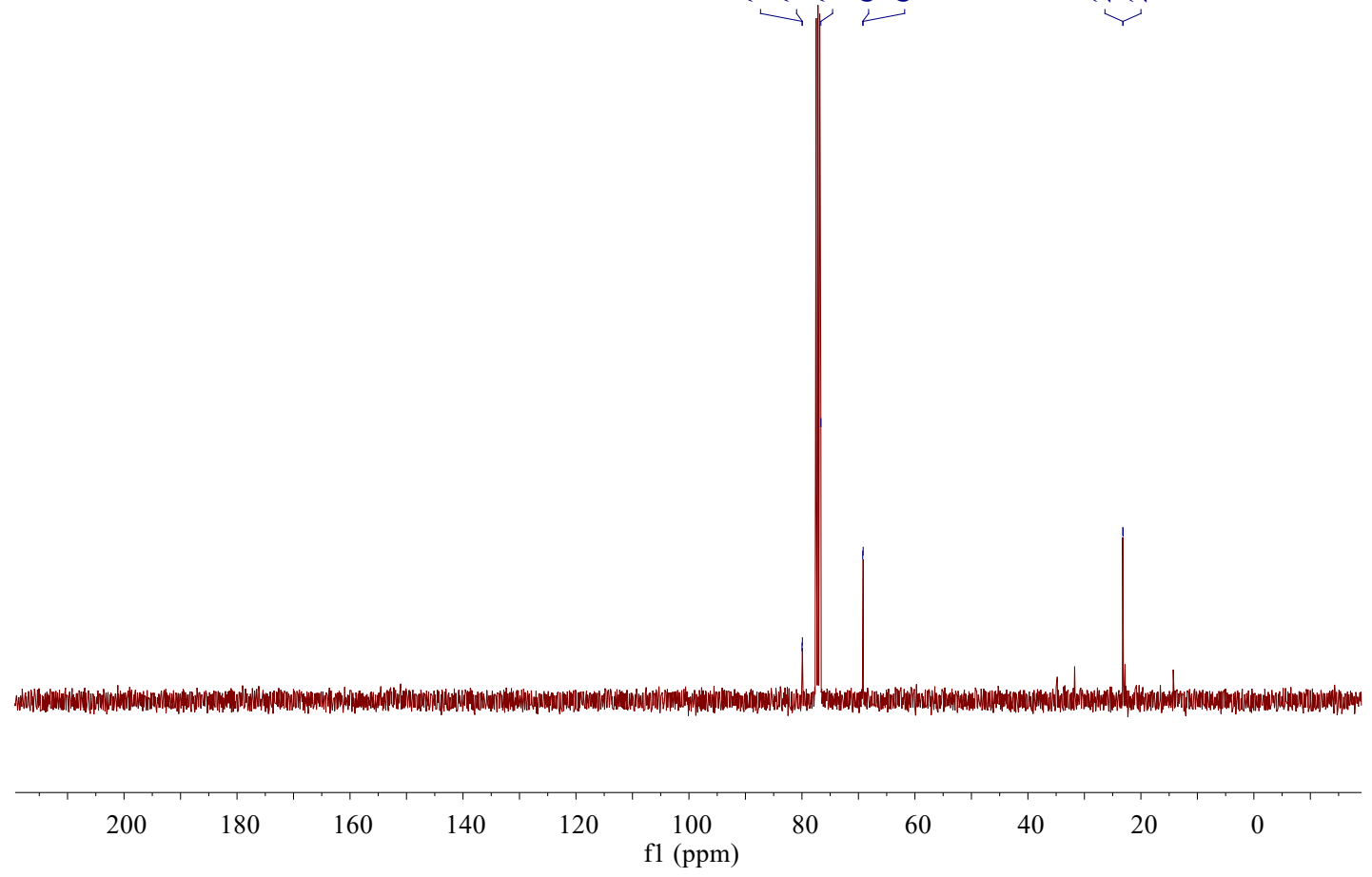


${ }^{31} \mathrm{P}$ NMR of $9\left(\mathrm{CDCl}_{3}, 162 \mathrm{MHz}\right)$

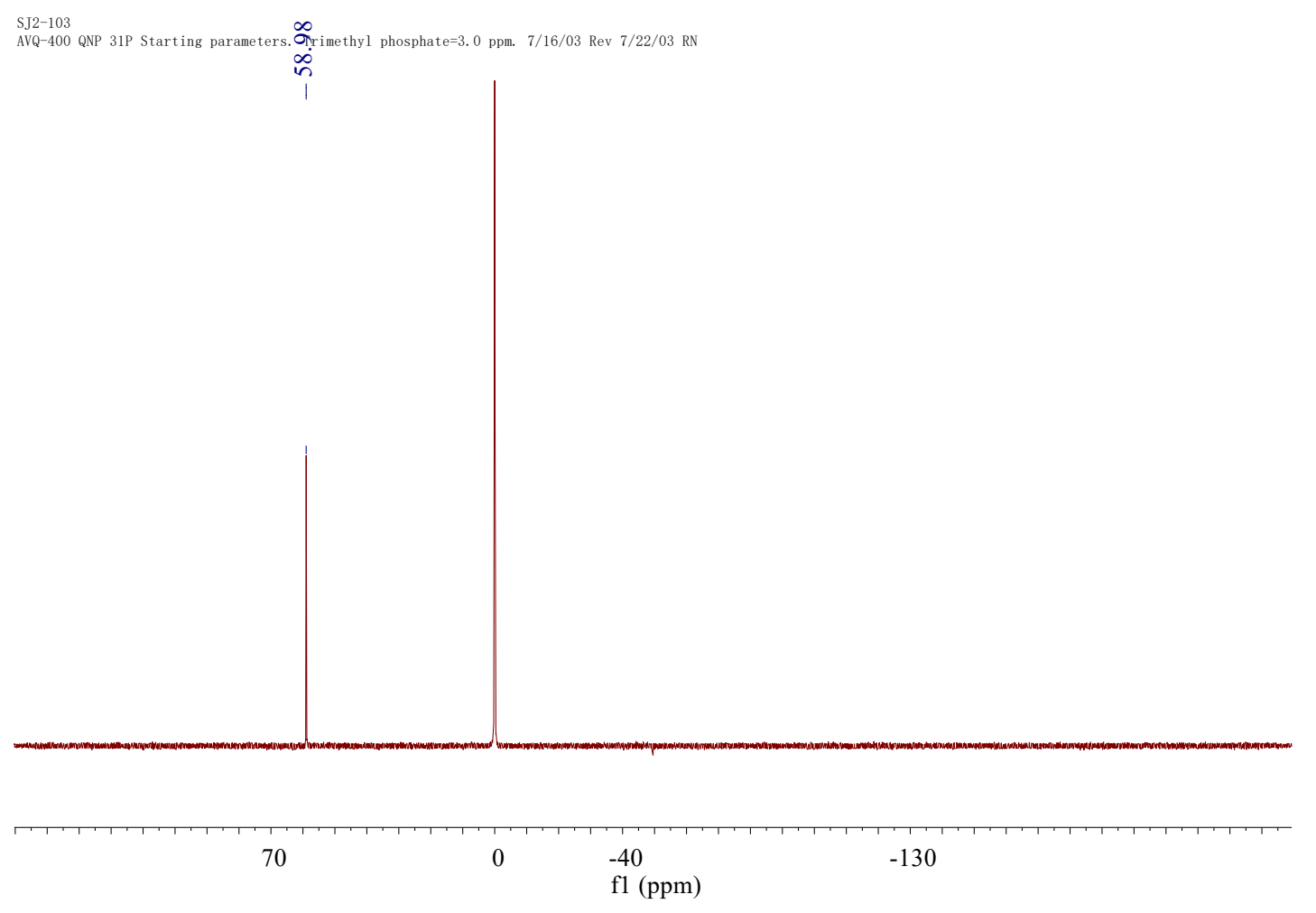

\section{References}

(1) Marty, M. T.; Baldwin, A. J.; Marklund, E. G.; Hochberg, G. K. A.; Benesch, J. L. P.; Robinson, C. V. Bayesian Deconvolution of Mass and Ion Mobility Spectra: From Binary Interactions to Polydisperse Ensembles. Anal. Chem. 2015, $87 \quad$ (8), 4370-4376. https://doi.org/10.1021/acs.analchem.5b00140.

(2) Eng, J. K.; Jahan, T. A.; Hoopmann, M. R. Comet: An Open-Source MS/MS Sequence Database Search Tool. PROTEOMICS 13 (1), 22-24. https://doi.org/10.1002/pmic.201200439.

(3) Čepa, M. Segmentation of Total Cell Area in Brightfield Microscopy Images. Methods Protoc. 2018, 1 (4), 43. https://doi.org/10.3390/mps1040043.

(4) Hounsou, C.; Margathe, J.-F.; Oueslati, N.; Belhocine, A.; Dupuis, E.; Thomas, C.; Mann, A.; Ilien, B.; Rognan, D.; Trinquet, E.; et al. Time-Resolved FRET Binding Assay to Investigate Hetero-Oligomer Binding Properties: Proof of Concept with Dopamine D1/D3 Heterodimer. ACS Chem. Biol. 2015, 10 (2), 466-474. https://doi.org/10.1021/cb5007568.

(5) Grandjean, C.; Boutonnier, A.; Guerreiro, C.; Fournier, J.-M.; Mulard, L. A. On the Preparation of Carbohydrate-Protein Conjugates Using the Traceless Staudinger Ligation. J. Org. Chem. 2005, 70 (18), 7123-7132. https://doi.org/10.1021/jo0505472. 